Chapter 5.

\title{
Practical implementation of the constructivist blended learning approach to teaching English for Specific Purposes at tertiary schools
}

In the preceding chapters the entire teaching/learning practice in a constructivist blended learning ESP course has been fully described in what concerns the selected learning content and the learning activities used - with the practical instances of both as exemplified in an ESP course for future psychologists and in a similar course for future economists and businesspeople.

What remains to be described in this chapter is the organizational aspect, i.e., how the course as a whole is organized. In this description, the same two ESP courses (for future psychologists and for future economists and businesspeople) that have been discussed throughout this monograph should again be used as practical examples. The best way of presenting such a description would be to demonstrate a kind of model of the course on the basis of one teaching/learning unit because every ESP course is organizationally made up of a number of teaching/learning units that are at least quite similar, if not identical, to each other as to their structure. Therefore, the model of one typical unit may completely represent the entire ESP course if that model comprises: the standard structural (organizational) parts of the unit, the objectives pursued by the teacher and the students when working on each of the parts, and the learning activities used in in-class and out-of-class work while working on those parts.

The learning content, except the content objectives pursued when working on a unit in the course, need not be elucidated in the model if it is clear what it is for the entire course (as it is clear for both ESP courses - for future economists/businesspeople and for future psychologists - used as examples in this monograph from what has been said about their learning content in the preceding chapters). But the model should clarify the number of in-class and out-of-class academic hours planned to be spent on working on one teaching/ learning unit and on each of its structural parts. The other relevant organizational information should also be clarified - such as the year of university studies for which the ESP course is designed, the total number of planned academic hours for in-class and out-of-class students' work in the course, whether there are some other classes, besides those included into the standard structure of work on every teaching/learning unit, and how the end-of-the-semester, end-of-thecourse testing/checking of skills acquired by students is organized. 
For developing the model in question, the optimal way is using the teaching/ learning units from the coursebooks analyzed in this monograph: Business Projects (Tarnopolsky, Kozhushko, et al., 2002) and Psychological Matters (Tarnopolsky, Kozhushko, et al., 2011a). This is because the basic coursebook that is used for organizing whatever ESP course, as a rule, best represents its design and structure. At any rate, this is so for the two ESP courses developed by us.

However, it should be remarked that in our case, it is not enough to develop only one such generalized model using one of the two coursebooks mentioned above or both of them together. It is because the ESP courses developed on their bases represent two different versions of the constructivist approach. It has already been said that the coursebook Business Project represents its earlier version elaborated without the use of blended learning. The complete version of the approach as described in this monograph is embodied in the coursebook Psychological Matters. There are also other differences between the two versions. For instance, the version of the ESP course for future economists and businesspeople is to a great extent based on continuous simulation (c.f. Chapter 1, 2.2.3 and 2.3.2) which is not used at all in the ESP course for students majoring in Psychology.

Therefore, it is necessary to present not one but two models in this chapter, each one representing one particular version of an ESP course. It is better to begin with the model of an ESP course developed for future psychologists because only that course represents the complete version of the constructivist blended learning approach to ESP teaching analyzed in the monograph (in this case, the other model of the course for economists will be good for the purposes of comparing and contrasting). This first model is discussed in the following section.

\section{The model of an ESP course based on the complete version of the suggested constructivist blended learning approach}

The ESP course for future psychologists was developed for the second year of their university studies and the second year of their learning English at university. (The first year, as mentioned already, is devoted to teaching General English with the aim of bringing learners to the B2 level of its command before ESP teaching/learning even starts.) The ESP course for students majoring in Psychology is designed for 144 academic hours of in-class work and the same number of hours of learners' out-of-class work ( 288 hours total -9.5 credits). Classes are held two times a week, two academic hours for every class (an academic hour is considered to be $\mathbf{4 0}$ minutes, so there are four academic hours of in-class work 
per week and four hours of learners' out-of-class work per week- eight hours total).

The course is organized on the basis of the coursebook Psychological Matters (Tarnopolsky, Kozhushko, et al., 2011a\&b) that consists of: 1) the Student's Book (designed exclusively for learners' in-class work) together with 2) the Workbook to it (meant for out-of-class students' assignments - home tasks); 3) a CD with audio recordings to be used in the teaching/learning process; and 4) the Teacher's Book with the description of the course and the discussion of the methodology of working on it, as well as with some additional materials to be used by the teacher for in-class and out-of-class work, lesson plans, lesson instructions, and explanations for the teacher, sample correct answers to a number of tasks in the Student's Book and Workbook, tapescripts of all the audio materials on the $C D$, and the unit glossaries of the most important vocabulary in the course.

The coursebook Psychological Matters and, consequently, the ESP course based on it are divided into four modules and ten units. The names of the modules and the units in them have been given in preceding Chapter 4 . The exact number of academic hours planned for working on each of the four modules is beside the point in the context under discussion, all the more so that different modules have various number of units in them (see Chapter 4, section 1), and that inevitably makes for the differences in time allocated for working on different modules. But the academic time planned for work on every unit is stable: it is 14 academic hours of in-class work (seven two-hour class periods) and 14 academic hours of students' autonomous out-of-class work ( 28 academic hours total). Therefore, 10 units require 140 academic hours of in-class work (out of planned 144 - see above) and 140 academic hours of students' autonomous out-of-class work ( 280 academic hours total out of 288). The remaining four hours of in-class work and four hours of out-of class work are divided between two Recapitulation Classes that will be discussed further.

Every unit in the coursebook and the course consists of seven parts, and two academic hours of in-class and two hours of out-of-class students' work are planned for each of the parts. That makes the above-indicated total of 28 academic hours per one learning unit. Since all the learning units are identical as to their structure, objectives pursued, and the learning activities used, the model of one typical learning unit, as already said, represents the model of the entire constructivist blended learning ESP course for future psychologists. This model is shown in Table 1.

As can be seen from the model in Table 1, every learning unit in the ESP course and coursebook for students majoring in Psychology fully reflects everything described in the preceding chapters of this monograph in what concerns the practical implementation of the constructivist blended learning approach.

However, such implementation of the approach also requires special components in the teaching/learning process aimed at checking and assessing 


\begin{tabular}{|c|c|c|}
\hline 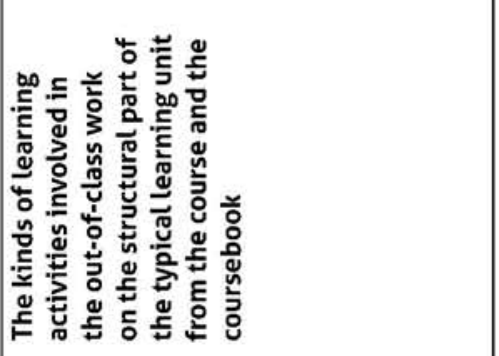 & in & 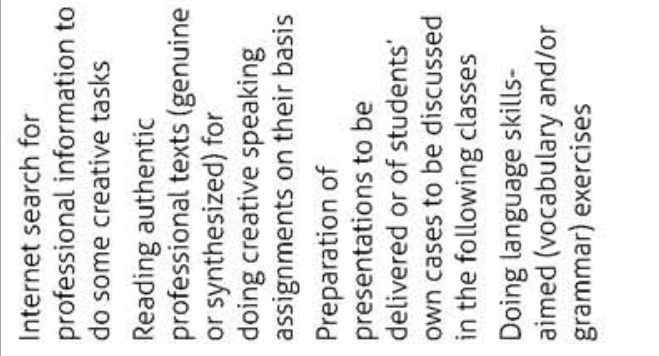 \\
\hline 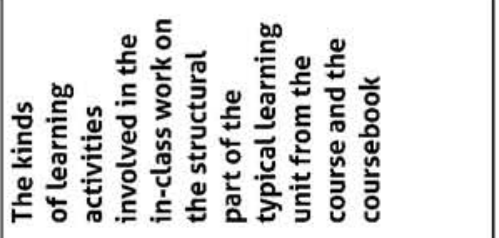 & $\checkmark$ & 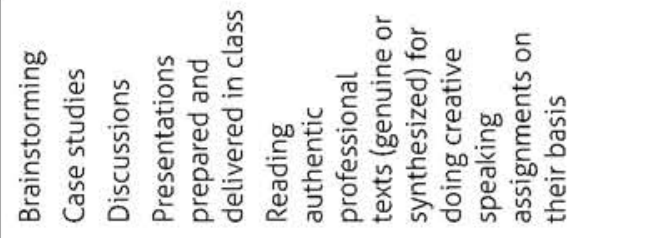 \\
\hline 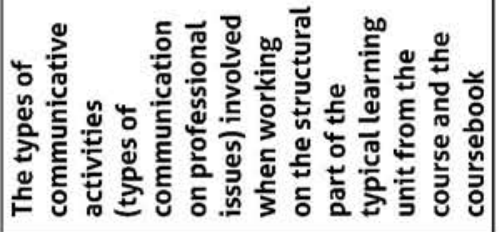 & $m$ & 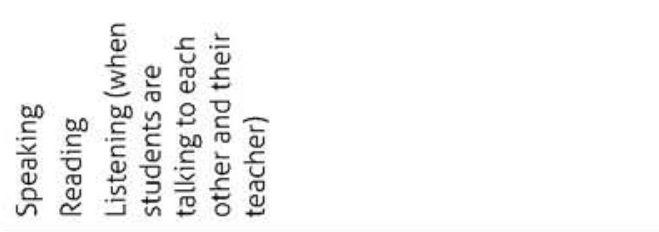 \\
\hline 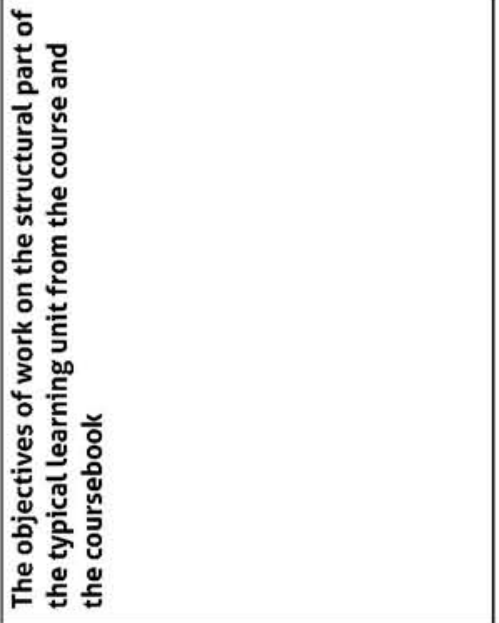 & $N$ & 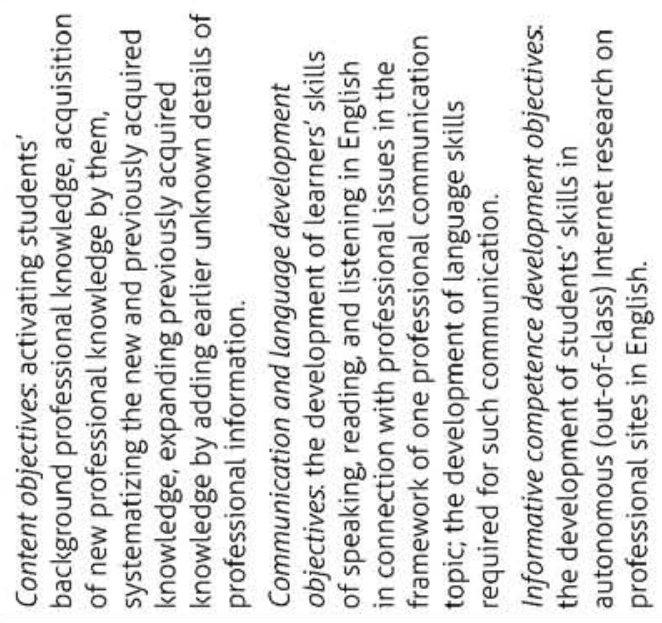 \\
\hline 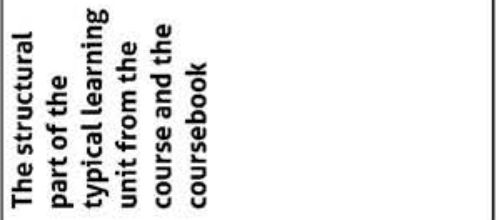 & $H$ & 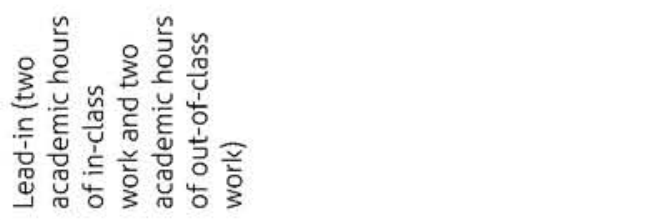 \\
\hline
\end{tabular}




\begin{tabular}{|c|c|}
\hline in & 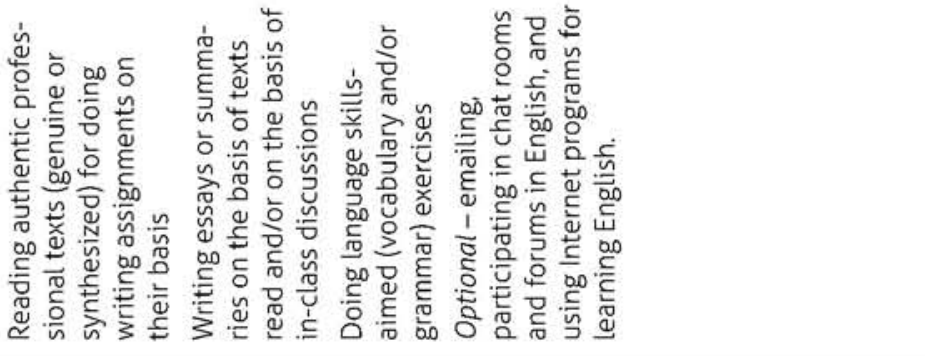 \\
\hline$\checkmark$ & 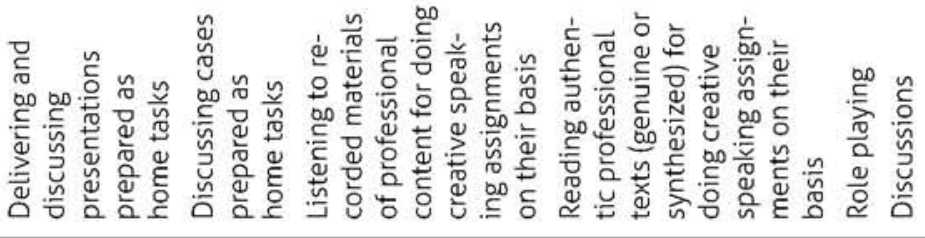 \\
\hline$m$ & 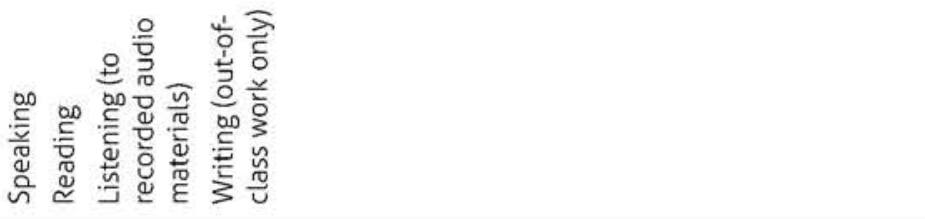 \\
\hline$N$ & 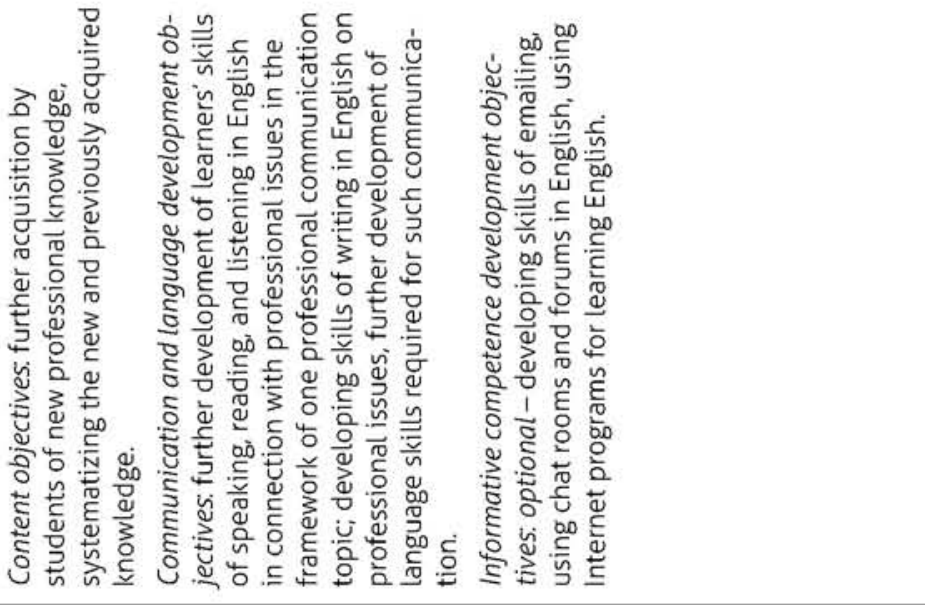 \\
\hline - & 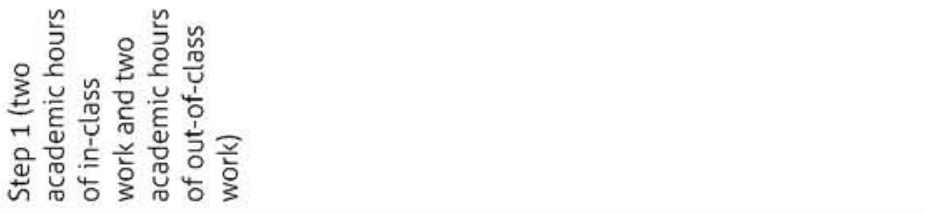 \\
\hline
\end{tabular}




\begin{tabular}{|c|c|}
\hline in & 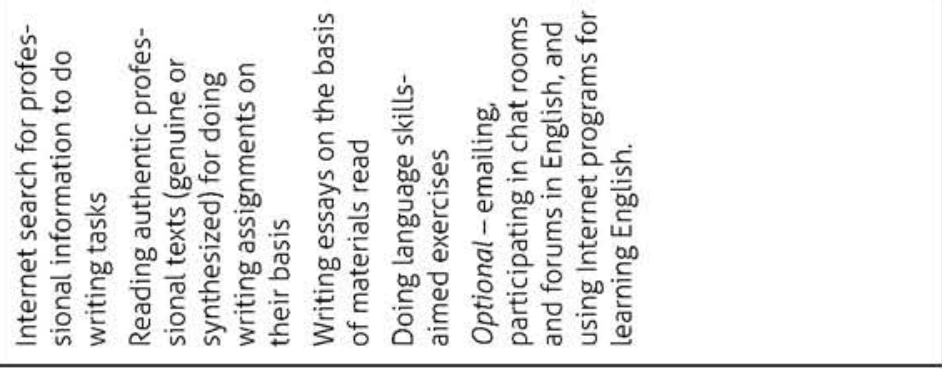 \\
\hline$\checkmark$ & 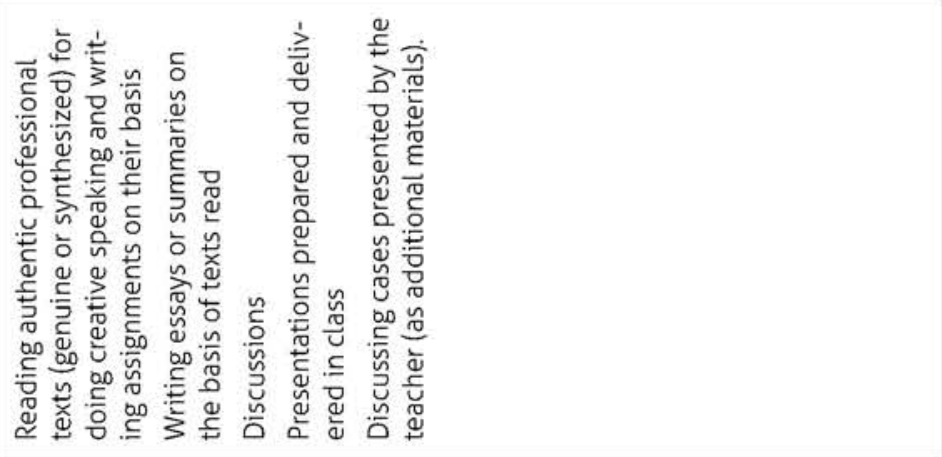 \\
\hline$m$ & 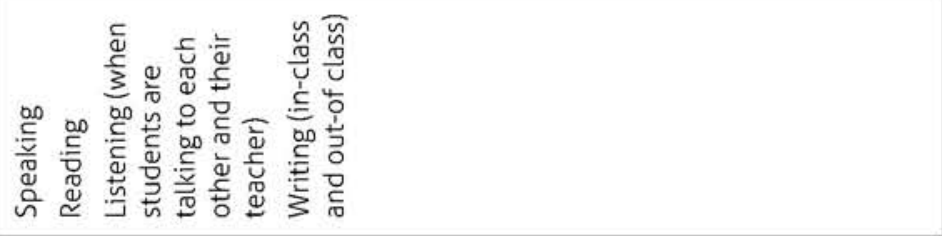 \\
\hline$N$ & 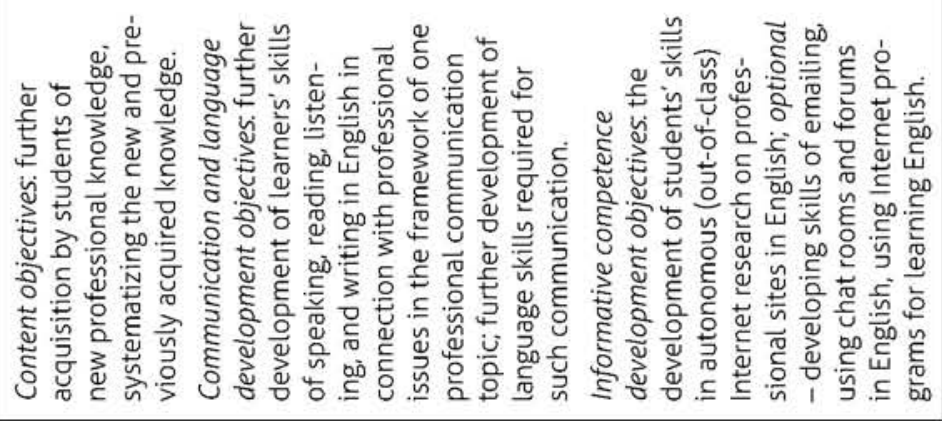 \\
\hline - & 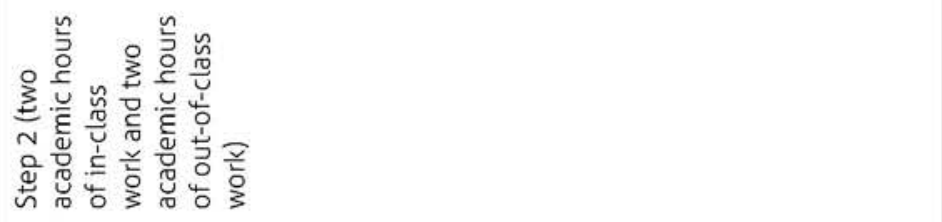 \\
\hline
\end{tabular}




\begin{tabular}{|c|c|}
\hline in & 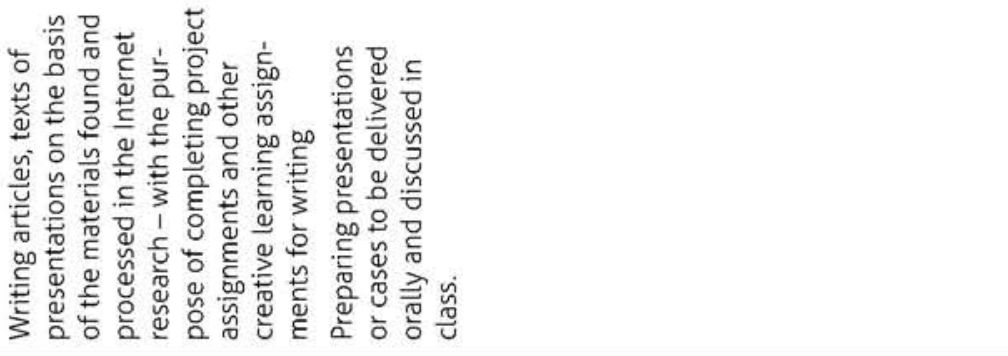 \\
\hline$\checkmark$ & 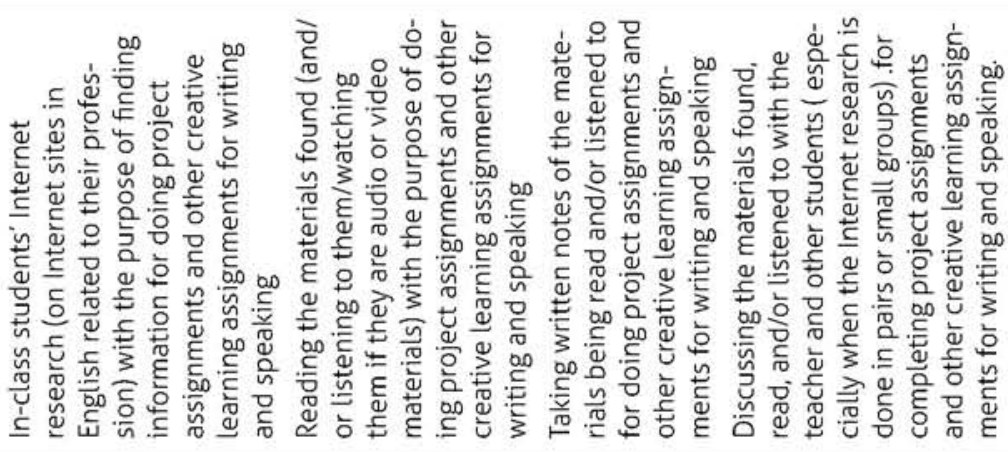 \\
\hline$m$ & 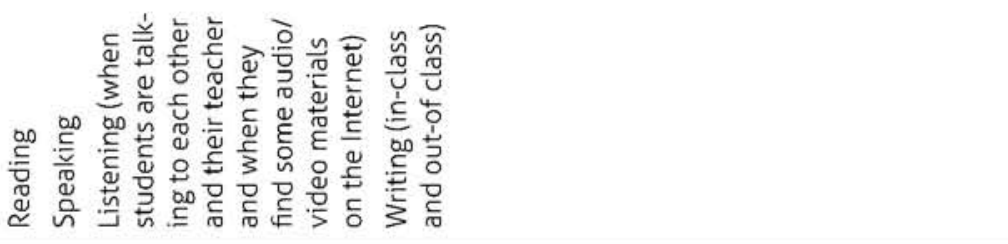 \\
\hline$N$ & 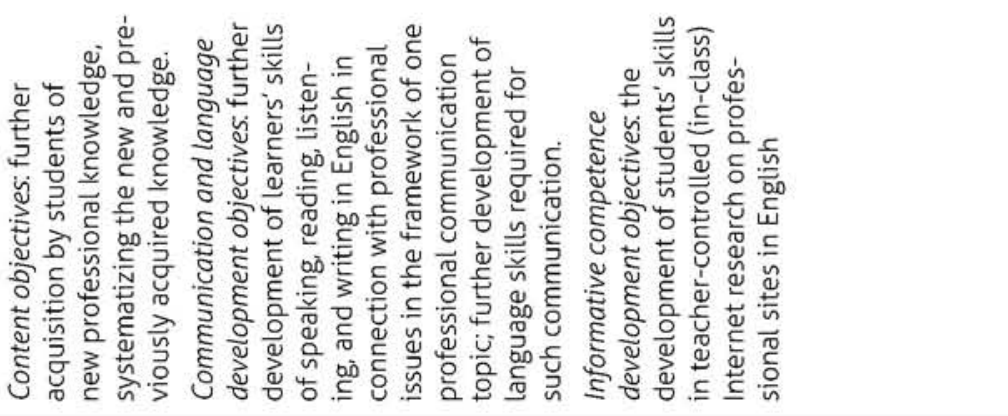 \\
\hline -1 & 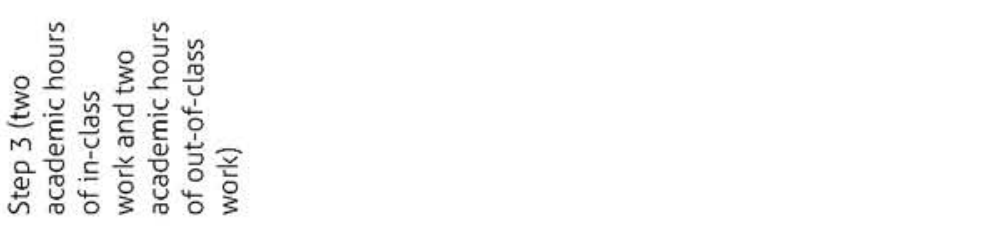 \\
\hline
\end{tabular}




\begin{tabular}{|c|c|}
\hline in & 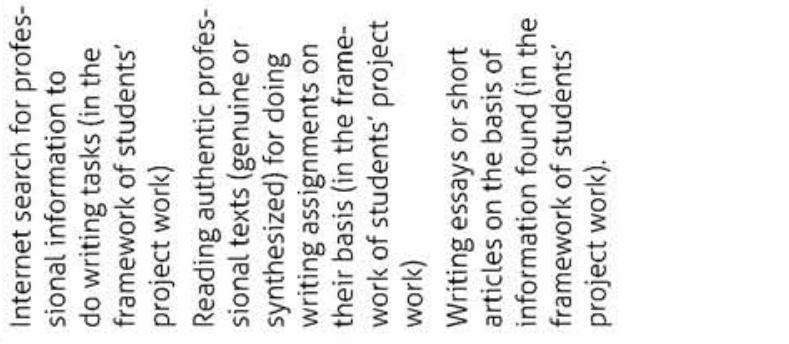 \\
\hline$\checkmark$ & 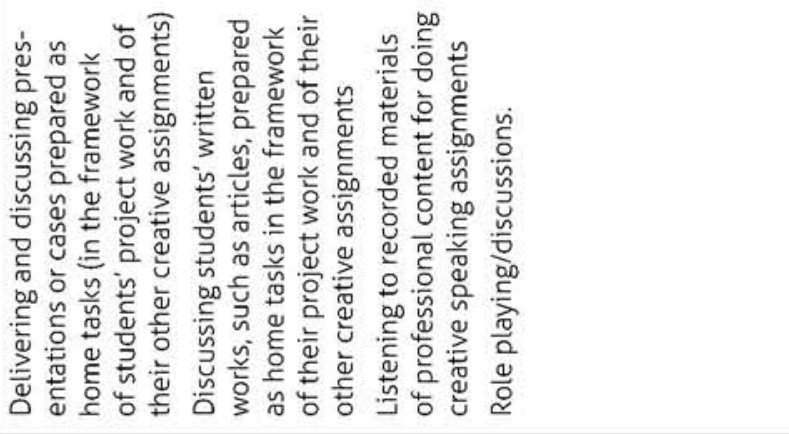 \\
\hline$m$ & 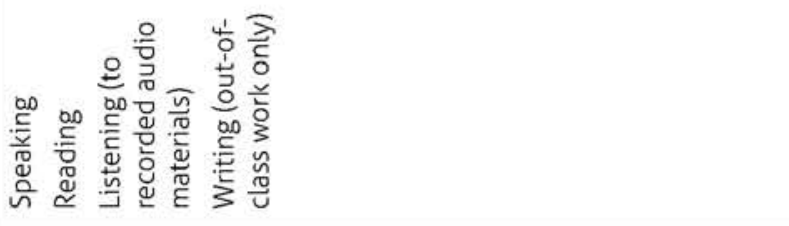 \\
\hline$N$ & 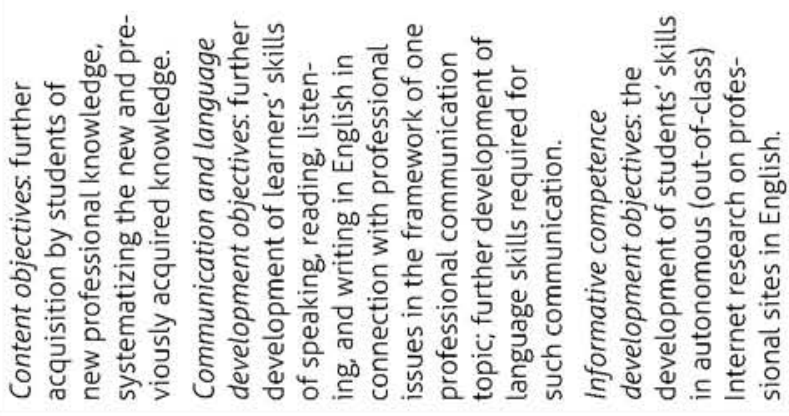 \\
\hline-1 & 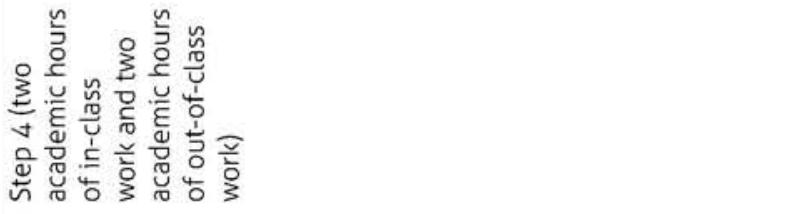 \\
\hline
\end{tabular}




\begin{tabular}{|c|c|}
\hline in & 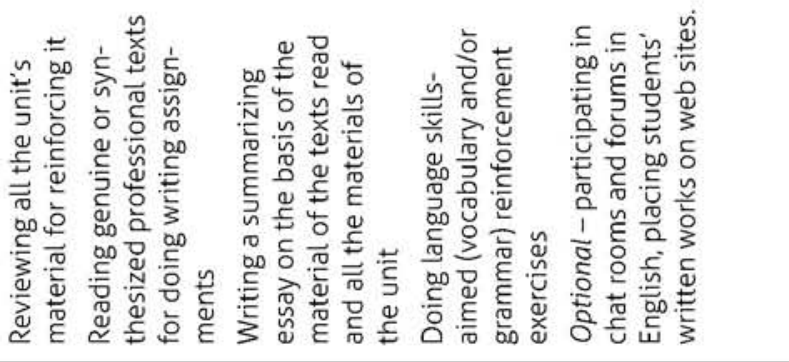 \\
\hline$\checkmark$ & 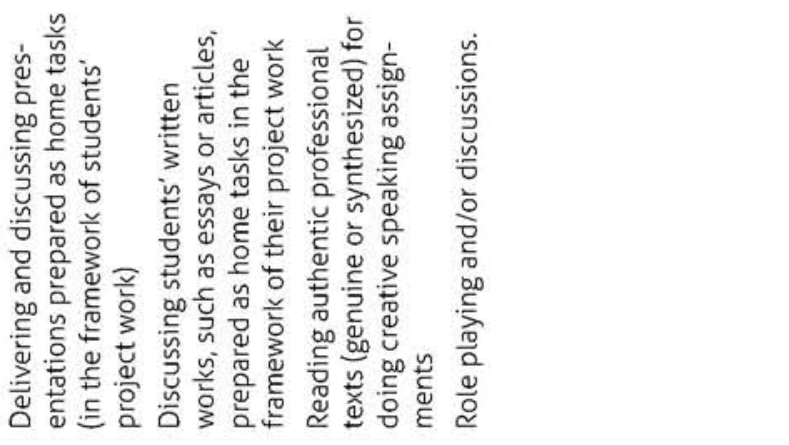 \\
\hline$m$ & 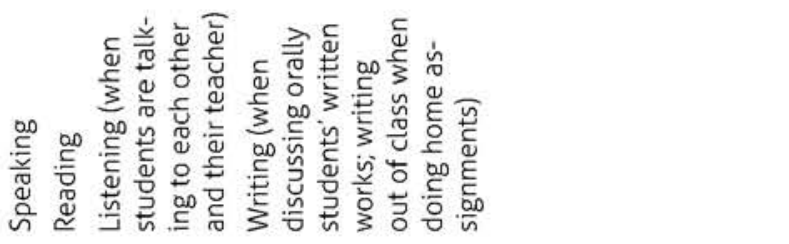 \\
\hline$N$ & 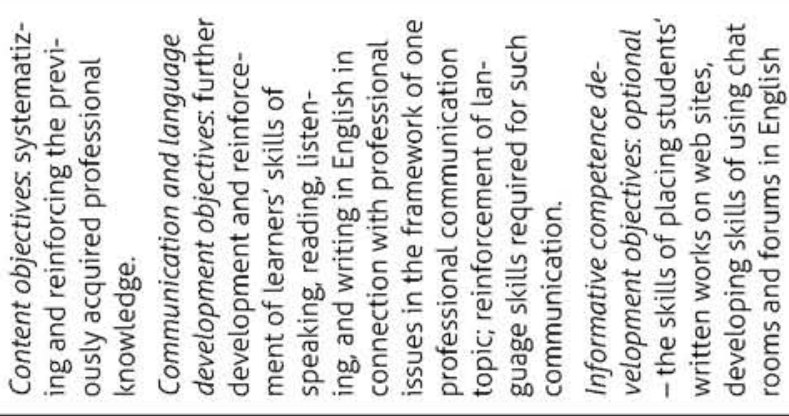 \\
\hline - & 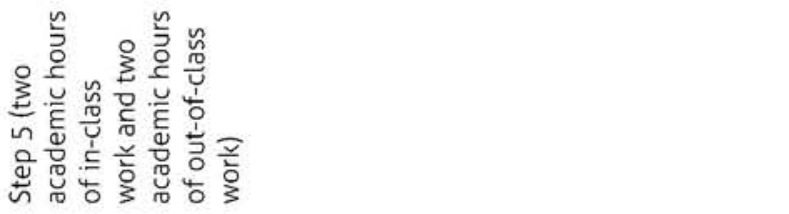 \\
\hline
\end{tabular}




\begin{tabular}{|c|c|}
\hline in & 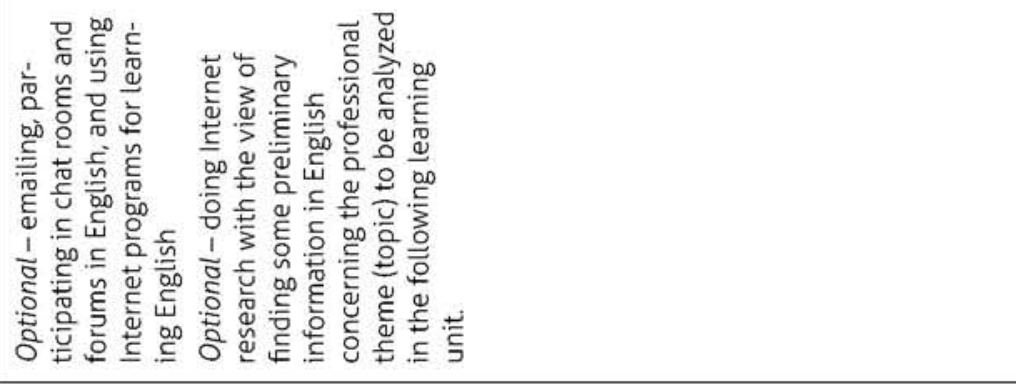 \\
\hline v & 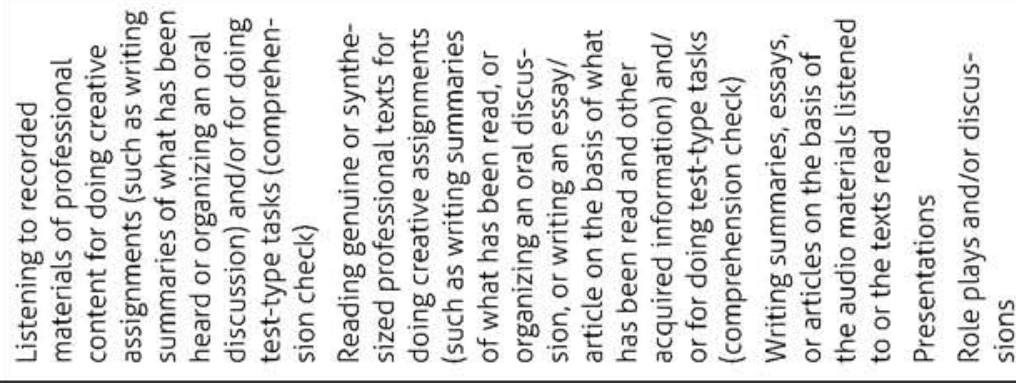 \\
\hline m & 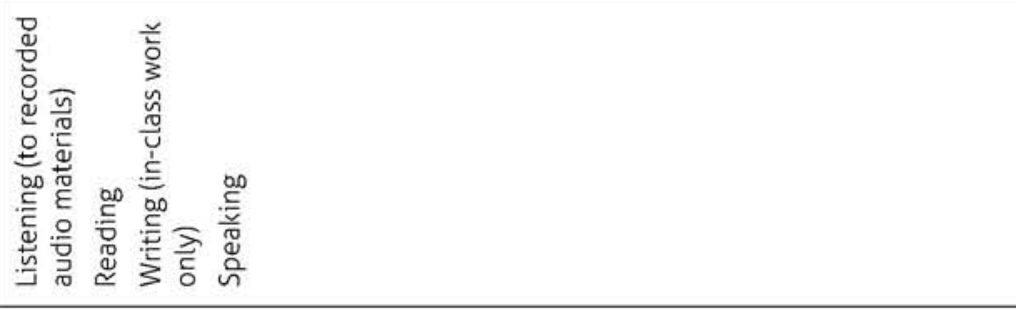 \\
\hline$N$ & 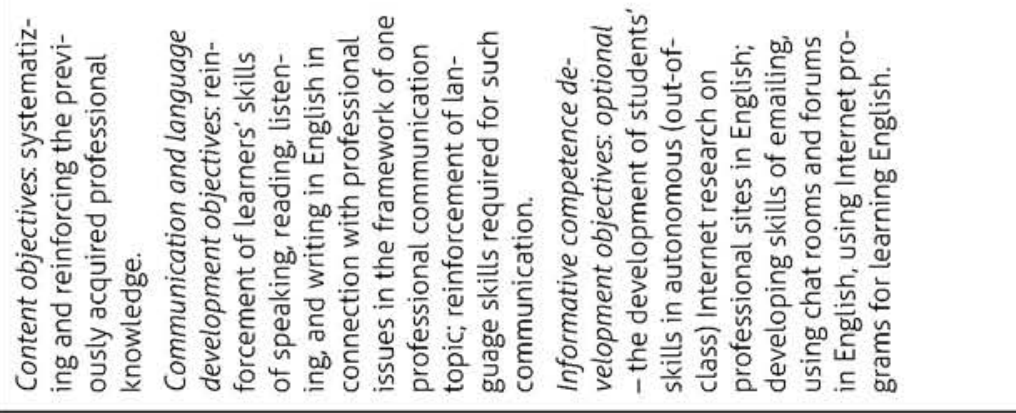 \\
\hline- & 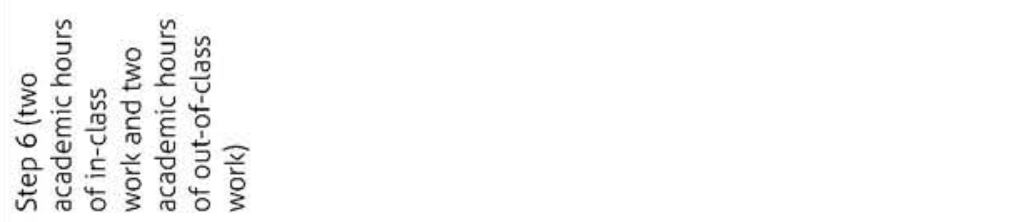 \\
\hline
\end{tabular}


the students' learning outcomes. Of course, checking and assessment are done during every class period because students' completion of every learning task demonstrates the level of their communication and language skills development giving the teacher sufficient opportunities for current, class-after-class, learners' assessment. Besides, as it is clear from the description of the last part (Step 6) in every learning unit, checking and assessment are one of its major purposes because the learning tasks are designed so that their completion can faithfully demonstrate everything the learners have managed to learn and acquire in the process of working on the unit that they are finishing with that generalizing Step 6 (c.f. Table 1).

Nevertheless, as every properly organized course, a constructivist blended learning ESP course is supposed to have class periods totally devoted to checking and assessment purposes. In the developed ESP course (and coursebook) for future psychologists this function is ascribed to the so called Recapitulation classes.

\subsection{Recapitulation classes as elements specially designed for checking, testing, assessing, and grading students' learning outcomes in an ESP course}

Two Recapitulation classes are planned for the ESP course for psychologists and included in the coursebook Psychological Matters. There is one Recapitulation class for every one of the two semesters (in the academic year as a whole) during which the course is being taught and learned. Their purposes are:

1. To recapitulate and generalize everything learned during the semester.

2. To assess the development of learners' communication skills acquired during the semester and check whether that development corresponds to the benchmarks pre-set for that particular semester. The communication skills are checked and assessed for all the four basic types of target language communication: speaking, listening, reading, and writing.

3. To assess the development of learners' language skills (primarily vocabulary and grammar) indirectly - as manifested when students are communicating in English orally or in writing, i.e., when they are speaking, writing, reading, or listening in that language. Direct checking and testing of language skills development (like in the Use of English paper of UCLES English language examinations - see, for instance, $F C E, 1997)$ is not practiced at all. It is considered to be against the experiential and communicative orientation of the course and also to be quite unnecessary. Learners' use and understanding of vocabulary and grammar when they are speaking, reading, listening, or writing in English is believed to be totally sufficient 
for assessing the development of students' language skills if there are appropriate criteria among those that are used for assessing their communication skills (see below).

4. To assess students' acquisition of the professional content matter (subject matter) of the course that is expected to be learned during the semester in parallel with target language communication and language skills.

As already noted, each of the two Recapitulation classes is planned for two academic hours of in-class work and two academic hours of out-of-class work. The in-class work is completely regulated by the assignments in the Student's Book from the coursebook Psychological Matters and instructions for the teacher in the Teacher's Book. Those assignments are aimed at productive types of communication only - speaking and writing - because they are considered to be the most difficult for students and most fully reflecting the overall development of their communication and language skills. Below, both tasks (one for speaking and the other one for writing) from Recapitulation class 1 (the end of the first semester of working on the ESP course for students of Psychology) in the Student's Book of the coursebook Psychological Matters (Tarnopolsky, Kozhushko, et al., 2011a) are given as examples:

\section{Recapitulation Class}

(Speaking and Writing)

1. The class is divided into two groups. The first group of 6-8 students is, in its turn, divided into two subgroups of 3-4 students in each. The first subgroup of 3-4 students have to prepare a short TV programme "Meet Psychology" for the Discovery Channel. In this programme they will need to tell the audience (the students from the other group of 6-8 persons) what psychology is, what its most important branches are, what the greatest landmarks in its history in the $20^{\text {th }}$ and $21^{\text {st }}$ centuries are lone student can give a 3-minute presentation on psychology as a science and art, another on branches of psychology, the third on the greatest landmarks in its history in the $20^{\text {th }}$ and $21^{\text {st }}$ centuries, the fourth summarizes everything said by his/ her partners and makes a conclusion concerning the importance of psychology in the world of today). This subgroup has 15 minutes for preparing their presentations. During the same time the second subgroup of the first group prepares a 5-7 minute quiz show "What do you know about psychology?" as a continuation to the programme "Meet Psychology." They prepare 8-10 questions on psychology as a science and art, branches of psychology, and its history to be put to the audience.

During the 15 minutes given to the first group for preparation, the second group of 6-8 students are preparing too. They are also divided into two subgroups of 3-4 students in each. The first subgroup of 3-4 students has to prepare a short TV programme "Psychology in the Workplace" for the Discovery Channel. In this programme they will need to tell the audience (the students from the first group of 6-8 persons) about the most frequent psychological problems at workplace (job 
burnout, work-family conflicts, employment and working place conflicts) and ways of dealing with such problems. One student can give a 3-minute presentation on job burnout and ways on dealing with it, another on work-family conflicts, the third on employment and working place conflicts, the fourth summarizes everything said by his/her partners and makes a conclusion concerning the importance of psychology for ensuring normal and efficient work of people. During the same time the second subgroup of the second group prepares a 5-7 minute quiz show "What do you know about psychological problems at workplace?" as a continuation to the programme "Psychology in the Workplace." They prepare 8-10 questions on job burnout, work-family conflicts, employment and working place conflicts to be put to the audience.

After both groups finish their preparation, the first subgroup of the first group presents their programme "Meet Psychology." They have 12-13 minutes to deliver all their presentations. After the presentations are over, the second subgroup of the first group present their quiz show. They ask questions of the audience (the students from the other group of 6-8 persons) who need to compete in what concerns the speed and correctness of answering the questions. The student from the audience who has answered correctly the greatest number of questions will be proclaimed the winner of the quiz show. The time for the quiz show is 7-8 minutes.

When the first group finishes, the second group presents their programme and quiz show in an absolutely identical manner and in the identical time limits. In this case, there will also be one winner of the quiz show (now from the first group who will be the audience).

The total time for the activity is 50 minutes.

2. Now every student has to individually write a review of the TV programme and quiz show that he or she has just watched (the students from the first group in the assignment 1 above write a review of the programme "Psychology in the Workplace" and the quiz show "What do you know about psychological problems at workplace?"; the students from the second group in the assignment 1 above write a review of the programme "Meet Psychology" and the quiz show "What do you know about psychology?").

Make each of your reviews of four paragraphs and of approximately 100 words.

You have 30 minutes for writing (until the end of the class). After finishing writing, hand in your written reviews to your teacher for his/her checking, commenting, and grading.

The above kinds of creative speaking and writing tasks for checking the level of students' relevant skills development were selected for inclusion into Recapitulation classes following several assumptions:

1. Assessing the level of learners' speaking and writing skills development can never be fully objective because such productive communicative activities are distinguished by too many variables that preclude the introduction of the quantitative assessment (like, for instance, in reading 
tests where choosing one correct answer out of several alternatives following the binary 'yes-no' paradigm is a clear quantitative indication of how accurately this or that testee has understood some fragment of the text after reading it). In speaking and writing, assessment can only be qualitative and, therefore, subjective - i.e., depending on every individual assessor's ideas of every particular quality parameter (c.f., for instance, Frendo, 2005: 123-125; Underhill, 1987; Wilds, 1975).

2. Qualitative assessment, i.e., the assessment based on some selected quality parameters, or criteria, is possible only when students-testees participate in productive communication: oral or written - speaking or writing (Alderson, Krahnke, \& Stansfield, 1987; Cohen, 1994; Madsen, 1983; 1983: Wilds, 1975).

3. The conditions of such communication should faithfully model, or imitate, the genuine conditions of using language in productive communication: oral or written-speaking or writing (Paltridge, 1992). In our case, it means that the conditions of communicating orally or in writing in the target language should imitate some of the conditions in which students may use that language in future in the course of their professional activities. Otherwise, judging whether the goals of teaching speaking or writing skills have been achieved may become impossible due to the difference between the checking/testing procedure and the real conditions of using the language in genuine communication (Savignon, 1992).

No special proof is needed to demonstrate that the kinds of tasks planned for Recapitulation classes fully meet the requirements above. But being creative in their nature and being very little externally regulated (and not being able to be different in that respect because, otherwise, those requirements will be neglected), such tasks make assessing students' results after doing them all the more subjective. This is because the level of assessment subjectivity naturally rises with the level of creativity and the level of learners' autonomy in the tasks being done - since the results of doing such tasks become more and more individualized, increasing accordingly the level of required assessment's individualization.

There are two ways of fighting that subjectivity, i.e., of making the assessment procedure as objective as possible when learners' target language skills in speaking and writing are being tested.

The first way is developing a whole set of qualitative parameters, or criteria, that every assessor/examiner is expected to take into account, so that they do their assessments on the basis of such criteria only (Cohen, 1994; Frendo: 125; Ingram, 1985:247). Moreover, a definite scale of points is supposed to be ascribed to every criterion, so that assessors/examiners are not free in their grading either (Cohen, 1994; Ingram, 1985: 247). Criteria and the scale of points attached to them give assessors/examiners clear-cut guidelines as to the assessment and 
grading procedure, thereby decreasing the impact of the subjective human factor in such assessment and grading (Underhill, 1987: 90).

The second way is the so called method of independent experts or judges when assessment and grading following a definite set of criteria and a definite scale of points is done not by the teacher who has been teaching the students but by some other teachers who do not know them at all - which also considerably lowers the degree of subjectivity. Its further decrease is achieved by letting not one but at least two independent experts or judges do the assessment and grading absolutely independently of each other. When the assessment procedure is completed, they negotiate their results/grades with each other arriving at some consensus - common grade which becomes the final grade for the student-testee. Alternatively, the points given to the student by every independent expert are all added up and then divided into the number of experts who were assessing and grading that student. The result of the division makes the final number of points (the final grade) scored by the learner (Underhill, 1987: 90).

Both these ways were used when developing the assessment and grading procedures for testing during Recapitulation classes the target language speaking and writing skills of students who majored in Practical Psychology.

The sets of criteria and the scales of points for assessing speaking and writing skills that had been developed were our own but they had been elaborated by analogy with similar criteria of other authors (such as Wilds, 1975) researching that issue and quoted above.

Thus, the set of criteria developed for assessing speaking skills includes seven such criteria, and ten points are ascribed to every criterion (all of them were considered to be of equal importance), so that a student-testee can score not more 70 points for doing the speaking task. If a student scores 63 points and higher ( $90 \%$ and higher), it is considered as an excellent result (an A grade). 56-62 points scored (between 80 and $89 \%$ ) are a good result - a B grade. 49-55 points (between 70 and $79 \%$ ) are a satisfactory result - a C grade, while the scores between 45 and 48 points (approximately between 65 and $68 \%$ ) make the borderline $D$ grade - pass. Everything lower than that is the $F$ grade - failure.

Every student is expected to be assessed for all his or her speaking in English that he or she has been doing during a definite Recapitulation class. Therefore, the seven suggested criteria are aimed at taking account of all aspects of students' speaking activities during that class. So, they comprise:

1. The criterion of content adequacy, i.e., how adequate, appropriate, and relevant in content matter what the student is saying is from the point of view of the theme (topic) being discussed, the situation in which that topic is being discussed, and the professional information that the students are supposed to know in what concerns the subject matter under discussion. 
2. The criterion of language adequacy, i.e., the relative linguistic accuracy and correctness of everything the student is saying from the point of view of grammar, vocabulary, and pronunciation. The relativity in this case means that all minor errors and mistakes which in no way interfere with communicative adequacy - complete and unhindered comprehensibility of what is being said - can be ignored by the assessor/examiner.

3. The criterion of temporal adequacy, meaning that student's speaking should be comparable as to the characteristics of its tempo with the normal average temporal characteristics of oral speech (220 words per minute on the average - Quené, undated); otherwise, the speech sounds too slow; examiners are supposed to assess the speech as temporally adequate empirically - if it does not seem to sound too slow to them).

4. The criterion of logical unity and coherence of what the student is saying, as well as the cohesion of their speech expressed by language means such as link words like: however, nevertheless, next, first of all, but, and, on the contrary, etc.

5. The criterion of variety of vocabulary and grammar used by the speaker.

6. The criterion of volume of speaking. That was a totally a priori criterion. It was supposed that the total time of every individual student's (out of a group of 10-12) speaking during one Recapitulation class was to be approximately five minutes which was considered enough to demonstrate the total range of the acquired speaking skills.

7. The criterion of comprehending the speech addressed to the speaker. Since, according to the speaking tasks in the Recapitulation class, every student is supposed to answer some questions (see above), correct understanding of speech/questions addressed to the speaker, as demonstrated by the manner in which he or she is answering, is considered to be an important speaking/listening skill.

The set of criteria and the assessment and grading approach to checking the development of writing skills, as demonstrated by students during a Recapitulation class, were elaborated in quite a similar manner to the ones applied to speaking tasks.

The set of criteria for assessing writing skills includes six such criteria, and, again, ten points are ascribed to every criterion, so that a student-testee can score not more 60 points for doing the writing task. If a student scores 54 points and higher ( $90 \%$ and higher), it is considered as an excellent result (an A grade). 48-53 points scored (between 80 and $89 \%$ ) are a good result - a B grade. $42-47$ points (between 70 and $79 \%$ ) are a satisfactory result - a C grade, while the scores between 39 and 41 points (approximately between 65 and $68 \%$ ) make the borderline D grade - pass. Everything lower than that is the $F$ grade - failure. 
The six criteria for assessing writing skills comprise:

1. The criterion of content adequacy, i.e., how adequate, appropriate, and relevant in content matter what the student has written is from the point of view of the theme (topic) s/he is expected to write about and the professional information that the students are supposed to know in what concerns the subject matter of their writing.

2. The criterion of formatting, composition, structure, and style adequacy meaning the degree of conformity of what the student has written to those formatting, composition, structure, and style requirements that are characteristic of writing this or that type of written documents in English (a summary, an abstract, an essay, a review, or an article, etc.).

3. The criterion of language adequacy, i.e., the linguistic accuracy and correctness of everything the student has written from the point of view of grammar, syntax, vocabulary, spelling, and punctuation. The requirements in this case are stricter than when assessing speaking because errors and mistakes in writing are less leniently looked upon by native speakers than in speaking. Therefore, not too many language mistakes can be ignored by the assessor/examiner, even if they in no way interfere with communicative adequacy - complete and unhindered comprehensibility of what has been written.

4. The criterion of logical unity and coherence of what the student has written, as well as the cohesion of the written document expressed by language means - such as link words like: however, nevertheless, next, first of all, but, and, on the contrary, etc.

5. The criterion of variety of vocabulary and grammar used by the writer.

6. The criterion of the size of the written work which is expected to be no less and not much more than $120-180$ words - in accordance with the norms existing for a number of international examinations, such as FCE, aimed at determining the level of learners' command of English.

For assessing students' speaking and writing skills checked during Recapitulation classes, when learners are working with the coursebook Psychological Matters, the involvement of independent experts or judges is also highly recommended. This procedure is routinely used at Alfred Nobel University in Dnipropetrovsk, Ukraine where that coursebook was first introduced into the ESP course for future psychologists. It needs no proof to assert that it greatly enhances the objectivity of testing results in comparison with the assessment by only one assessor/examiner - the teacher who has been teaching students during the semester or the academic year.

Testing the development of students' skills in target language listening and reading within the framework of Recapitulation classes discussed in this section of the monograph is recommended to be organized in quite a specific and different manner in comparison with checking speaking and writing skills. 
First, it is recommended to do such checking as out-of-class students' testing (it has been said before that, besides two academic hours of in-class work, two academic hours of out-of-class work are also planned for every Recapitulation class). Transferring the assessment of students' listening and reading skills to out-of-class work is rational because this assessment can best be done through the kind of testing that uses the quantitative, not qualitative, approach to obtain the most accurate and objective results (see below). There is no sense in wasting the short time of in-class Recapitulation class work on the procedure of standardized testing which can be implemented even in the teacher's absence. It is much better to use that short time for creative kinds of students' work aimed at better assessing their speaking and writing skills development - which can be done only in class and only in the teacher's presence.

Second, it is well known that checking the development of students listening or reading skills is best done through the procedure of standardized objective testing. Students begin by listening to some recorded audio material (a fragment of a psychological session or of a lecture, some kind of interview, etc.) or by reading some authentic professional text. There can be one or more texts to read or to listen to with every text for listening sounding not longer than five minutes and every text for reading containing not less than 500 and not more than 1,000 words (here, as in some other aspects - see above and below, - the norms set for international exams/tests of English are followed). After reading or listening, one or several test-type tasks are done by students, such as multiple choice tasks, gap-filling tasks, matching tasks, etc. For instance, one of the texts for listening used for the Recapitulation class described above was an authentic interview found on the Internet. A mother was interviewed about the psychology of her relationships with her son, Rupert. After 5-minute listening, students were requested to do the following multiple choice test task where correct answers to seven questions were supposed to be selected out of four suggested alternatives of each of the answers:

\section{Thinking about the time when Rupert was young, the interviewee regrets that}

A. she didn't become famous.

$B$. her career was affected.

C. she wasn't at home more.

$D$. she concentrated on her work.

\section{What was the interviewee's view of her husband when Rupert was young?}
A. She resented his closeness to Rupert.
$B$. She worried he would not cope.
C. She knew he would do what she told him to.
D. She appreciated what he did. 


\section{How did the interviewee react to the criticism of her as a mother?}
A. She lost her temper.
$B$. She made excuses for her behavior.
C. She explained the situation at home.
$D$. She kept quiet.

\section{How did Rupert behave as a little boy?}
A. He caused his mother a lot of worry.
$B$. He demonstrated a need to be active.
C. He had difficulty getting on with other children.
D. He was always looking for attention.

\section{The phrase 'ticking him off' means}
A. criticizing his behavior.
B. making fun of him.
$C$. disagreeing with his ideas.
D. threatening him.

\section{His parents first thought Rupert might make a good actor when he}
A. was asked to appear in the school play.
$B$. started to enjoy dressing up.
$C$. showed he knew what makes a good performance.
$D$. told them he enjoyed acting.

\section{What do we learn about Rupert's modeling career?}
A. It ended when he was offered an acting job.
B. It took time to develop.
$C$. It was encouraged by his mother.
D. It was the result of a childhood ambition.

Every correct answer brought each of the students one point with seven correct answers earning them the highest A grade, while less than four correct answers meant a failure. Reading tests were organized in an absolutely identical manner - though it should be emphasized again that the test tasks both in reading and listening are not and need not necessarily be multiple choice but could be of other kinds, as already mentioned. It should also be remarked that in such an organization of testing students' listening and reading skills development we introduced nothing new but simply faithfully followed the existing practice of international examinations aimed at determining the level of learners' command of English - such as FCE, CAE, IELTS, TOEFL, and others.

Finally, the third, last, specificity of the developed procedure of testing listening and reading skills was due to the fact that, unlike testing speaking and writ- 
ing procedure, there are no materials for listening and reading and no test tasks to such materials in the Recapitulation classes sections from the coursebook Psychological Matters. The materials there are limited to the tasks for speaking and writing, like the ones given above. It is the teacher who is supposed to select texts for listening and reading to be used during the out-of-class work on Recapitulation classes. It is also the teacher who is supposed to develop test tasks for those materials - like the test task for listening demonstrated above. This is so because of three reasons:

a) materials for listening and reading tests, unlike those for speaking and writing tests, should be changed and replaced with the new ones quite often to remain reliable and valid for testing purposes; no coursebook can provide enough materials for such frequent replacements;

b) those materials should be as up-to-date as possible from the professional point of view which is the requirement of the content-based approach; no coursebook can ensure such frequent updating of testing materials;

c) it has already been mentioned that it was testing students' speaking and writing skills that was considered to be of principal importance for assessing their learning results (as the most difficult communication skills for development and those that best demonstrate learners' language proficiency); therefore, it was reasonable to give teachers opportunities of having wider choice and being more independent in organizing the checking of students' success in developing their listening and reading skills.

The procedure and requirements to organize checking, testing, assessing, and grading students' learning outcomes in a constructivist blended learning ESP course described above are most certainly not the only possible ones - there can be many others. So, they were analyzed not to show them as something mandatory for designing such a course. They are nothing more than examples of how such procedures can be organized to supply valid and reliable data for formulating judgments on students' successes or lack of them in their ESP studies. But those teachers who wish to introduce the constructivist blended learning approach into their ESP courses may develop a number of different procedures.

When discussing further the design of an ESP course for future economists and businesspeople, there will be no detailed analysis of the checking, testing, assessing, and grading students' learning outcomes procedure in that course, like it was done above (for the course aimed at future psychologists). This is because these procedures in both courses and both coursebooks ( $P$ sychological Matters and Business Projects) are identical. The only difference is the fact that in the ESP course for future economists and businesspeople there are more than two Recapitulation classes. Though the number of learning units in the course for economists is greater, the number of Recapitulation classes could be increased in it since the time for studying each of the units is shorter and there is no time spending on the Internet work (see the next section). In fact, the procedure just 
discussed was first developed for the Recapitulation classes in the coursebook Business Projects and the ESP course based on it. Afterwards, that procedure was reproduced for the Recapitulation classes in the coursebook Psychological Matters and the ESP course for future psychologists. This is why there is no need to discuss it again when analyzing the course for future economists and businesspeople.

However, that course itself needs to be discussed separately because of the difference in its design, structure, and even ideology as compared to the ESP course for psychologists developed later. The description and discussion are given in the next section of this chapter.

\section{The model of an ESP course based on the other (narrower) version of the suggested constructivist approach}

The ESP course for future economists and businesspeople, just like the course for future psychologists, was developed for the second year of learners' university studies and the second year of their learning English at university. That ESP course is also designed for 144 academic hours of in-class work and the same number of hours of learners' out-of-class work ( 288 hours total -9.5 credits) Classes are again held two times a week, two academic hours for every class ( 4 academic hours of in-class work per week and 4 hours of learners' out-of-class work per week -8 hours total).

The course is organized on the basis of the coursebook Business Projects (Tarnopolsky, Kozhushko, et al., 2002) that consists of: 1) the Student's Book (designed exclusively for learners' in-class work) together with 2) the Workbook to it (meant for out-of-class students' assignments - home tasks); 3) a CD/cassette with audio recordings to be used in the teaching/learning process; and 4) the Teacher's Book with the description of the course and the discussion of the methodology of working on it, as well as some additional materials to be used by the teacher for in-class and out-of-class work, lesson plans, lesson instructions, and explanations for the teacher, sample correct answers to a number of tasks in the Student's Book and Workbook, etc. In all these aspects, there is an absolute identity with the coursebook and course for future psychologists.

The differences begin with the number of modules and learning units. The coursebook Business Projects and the ESP course based on it are divided into more modules and units - six modules and twelve units: two units in every module. The names of the modules and the units in them have been given in preceding Chapter 4. Twenty academic hours of in-class work and twenty academic hours 
of out-of-class work are allocated for the first two modules. Correspondingly, the academic time planned for work on separate units in them is 10 academic hours of in-class work (five two-hour class periods) per unit and 10 academic hours of students' autonomous out-of-class work (20 academic hours total). All the other four modules, dealing with larger themes as to the scope of their content matter and content materials, have twenty four academic hours of in-class work and twenty four academic hours of out-of-class work allocated for each of them. Correspondingly, the academic time planned for work on separate units in those four modules is 12 academic hours of in-class work (six two-hour class periods) per unit and 12 academic hours of students' autonomous out-of-class work ( 24 academic hours total). Therefore, all 12 units require 136 academic hours of in-class work (out of planned 144 - see above) and 136 academic hours of students' autonomous out-of-class work (272 academic hours total out of 288). The remaining eight hours of in-class work and eight hours of out-of class work are equally divided between three Recapitulation Classes (each of them is held after two modules have been studied) and one End-Piece class - the last class period in the academic year designed absolutely identically with the Recapitulation classes though not on the materials of separate modules but on those of all the modules together. It is used to summarize and test the overall students' achievements in the academic year. As already said, all such classes will not be discussed further since they are designed and structured just like the Recapitulation classes in the ESP course for future psychologists.

Every unit from the first two modules in the coursebook Business Projects consists of five parts, and two academic hours of in-class and two hours of outof-class students' work are planned for each of the parts. Every unit from the following four modules consists of six parts, and two academic hours of in-class and two hours of out-of-class students' work are planned for each of the parts. That makes the above-indicated total of 20 academic hours per each of the first four learning units and 24 academic hours total for each of the following eight learning units in the course.

Everything said above demonstrates the organizational differences between the ESP course and coursebook for future economists and businesspeople and the already analyzed course and coursebook for future psychologists. Such differences are mostly formal in their nature.

However, more serious differences can be observed when the design and structure of the teaching/learning process, the different objectives pursued in that process, and the learning activities are analyzed.

To analyze them, it is again necessary to create a model of the teaching/ learning process similar to the model developed when discussing the design and structure of an ESP course for future psychologists. That new model can also be structured using as an example only one learning unit representing the entire learning process. The situation in this case is the same as with the ESP course for 
psychologists because all the learning units are, in all practical aspects, identical as to their structure, objectives pursued, and the learning activities used. Even the fact that the first four learning units are shorter than the other eight units that follow them does not change the identical nature of all units. The difference of the first four units is due only to the fact that students are given fewer texts to read and discuss both in and out of class and, therefore, there are fewer learning activities based on those texts. However, the learning activities, the unit design and structure, the teaching/learning objectives remain the same. Consequently, if the model is constructed on the basis of a more typical 'longer' learning unit of six parts (as a more frequent and, therefore, more representative sample than a 'shorter' unit of five parts), such a model can be considered as adequately demonstrating the entire constructivist ESP course and the entire constructivist teaching/learning process for future economists and businesspeople. The model in question is shown in Table 2.

What catches the eye in this model is its similarity to the model shown in Table 1 - the similarity testifying to the fact that both models, representing two versions of the constructivist approach to ESP course design, are 'blood relatives'. However, further comparison of those two 'blood relatives' demonstrates that they are certainly not 'twins' because there are two important differences that have already been briefly mentioned: the absence of mandatory work on the Internet in the second model and the absence of continuous simulation in the first one. There are also some other minor differences. Both the similarities and differences are such that deserve separate discussion presented in the following section. 


\begin{tabular}{|c|c|}
\hline 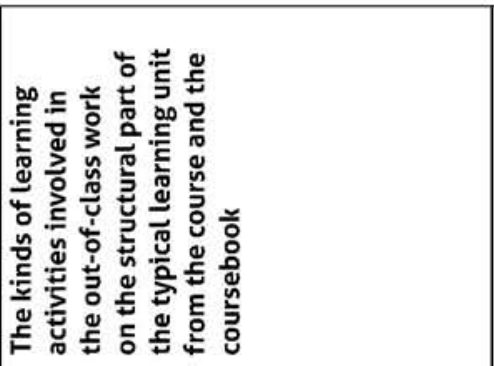 & 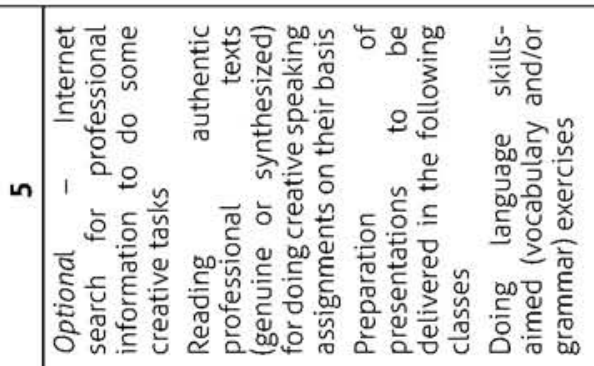 \\
\hline 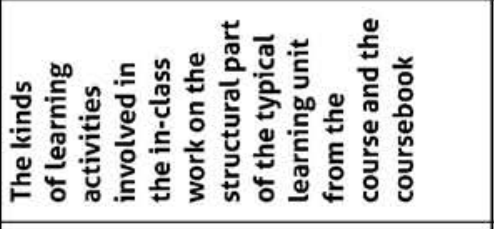 & 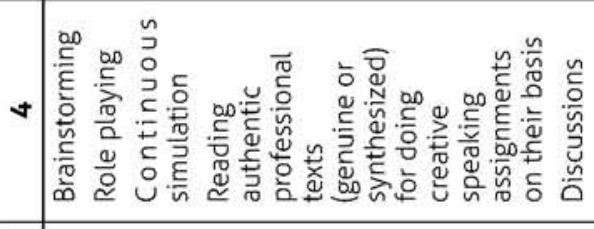 \\
\hline 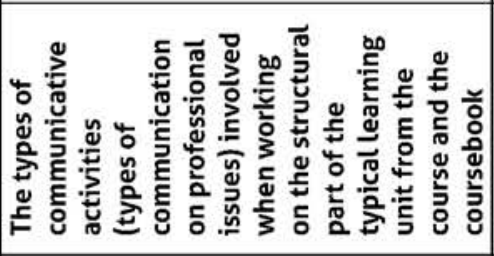 & 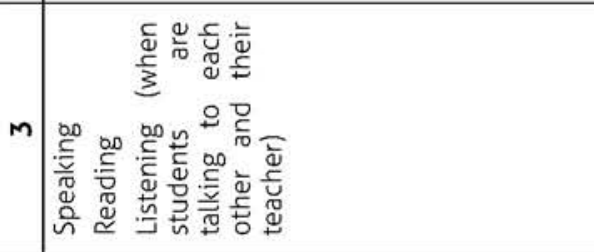 \\
\hline 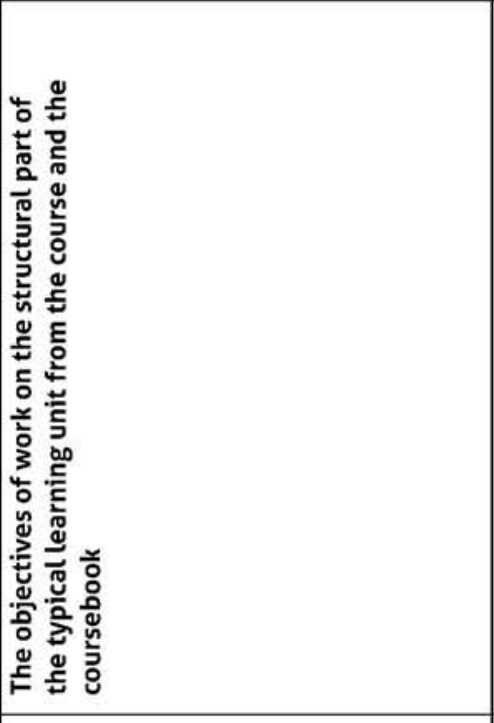 & 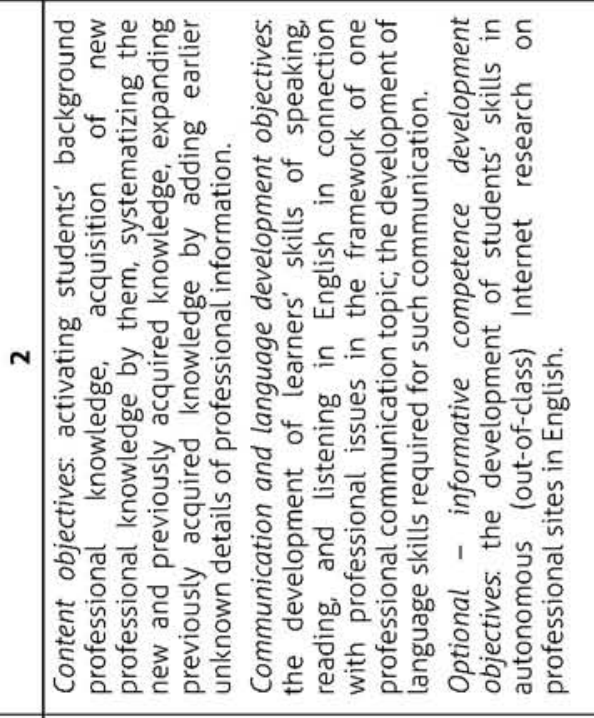 \\
\hline 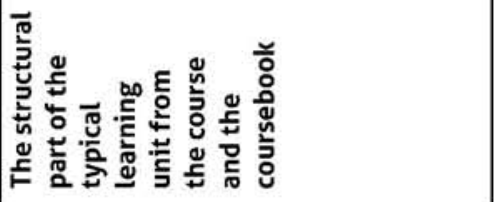 & 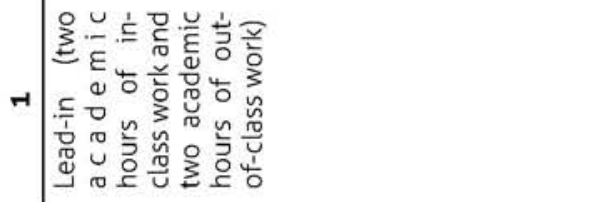 \\
\hline
\end{tabular}




\begin{tabular}{|c|c|}
\hline in & 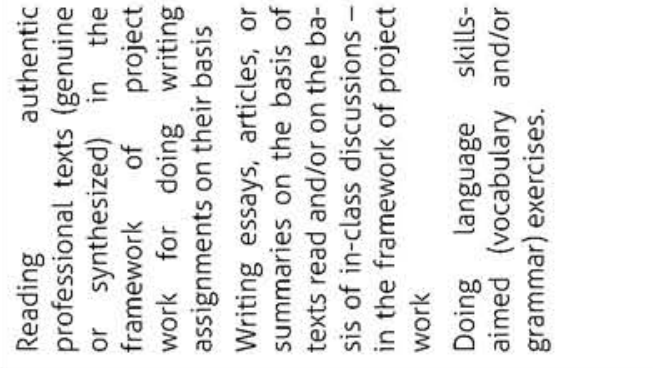 \\
\hline$\checkmark$ & 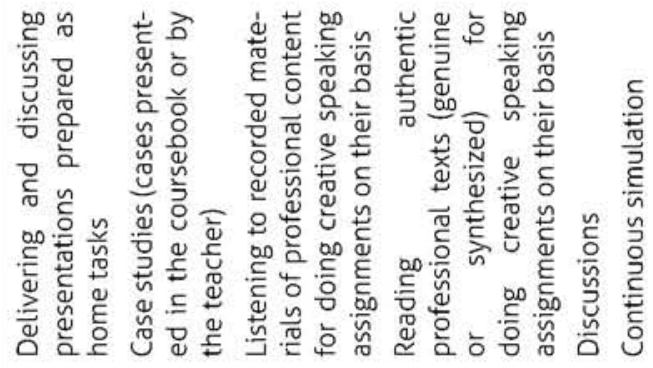 \\
\hline$m$ & 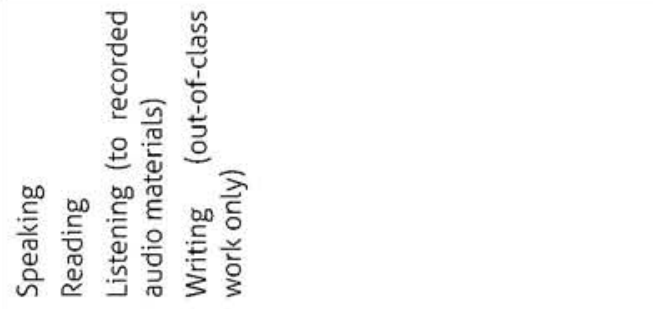 \\
\hline$N$ & 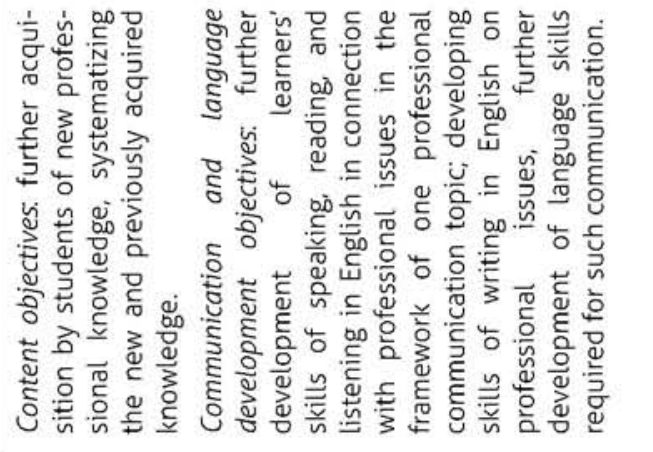 \\
\hline-1 & 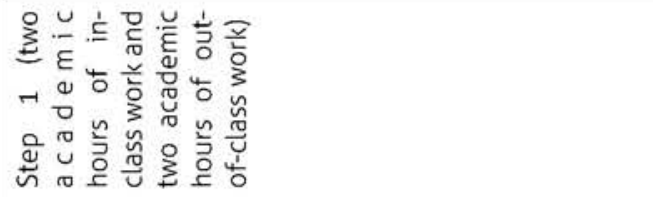 \\
\hline
\end{tabular}




\begin{tabular}{|c|c|}
\hline in & 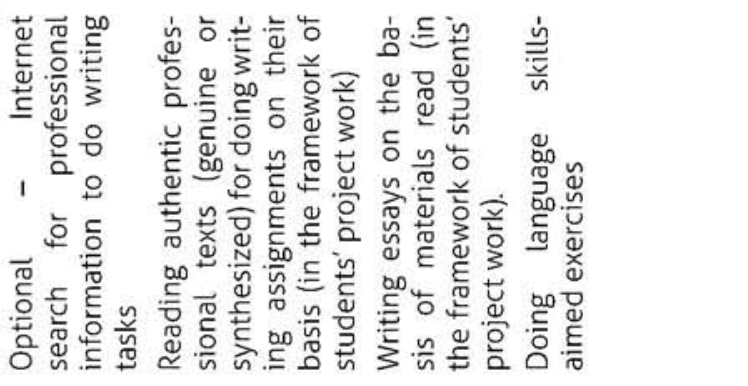 \\
\hline$\checkmark$ & 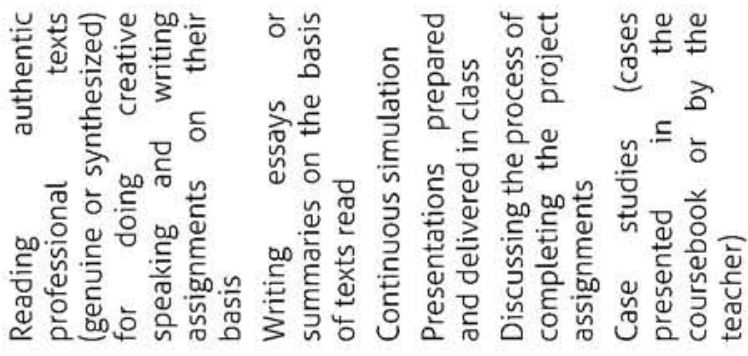 \\
\hline$m$ & 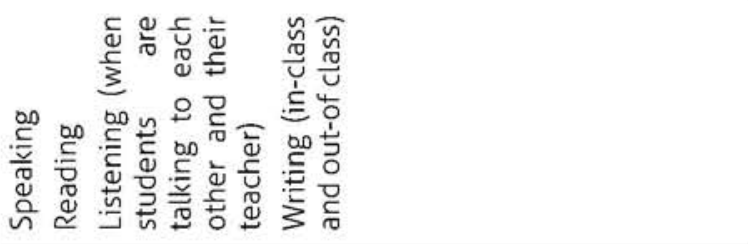 \\
\hline$N$ & 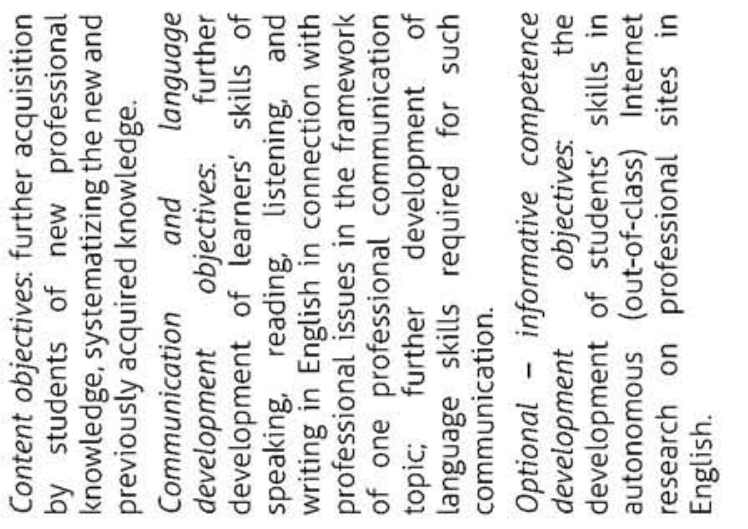 \\
\hline$-r$ & 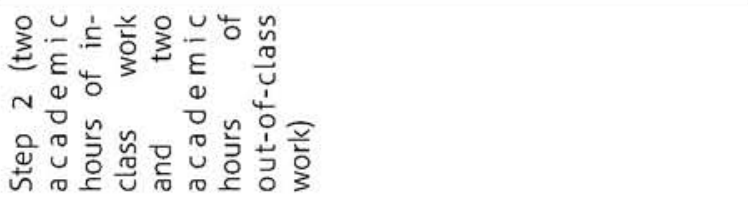 \\
\hline
\end{tabular}




\begin{tabular}{|c|c|}
\hline in & 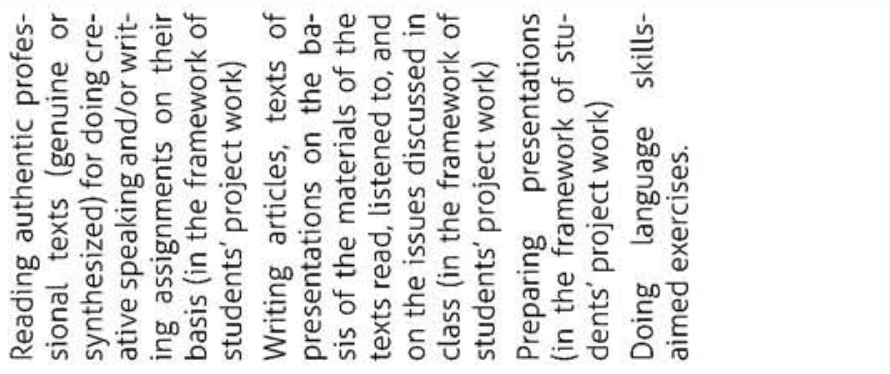 \\
\hline$\checkmark$ & 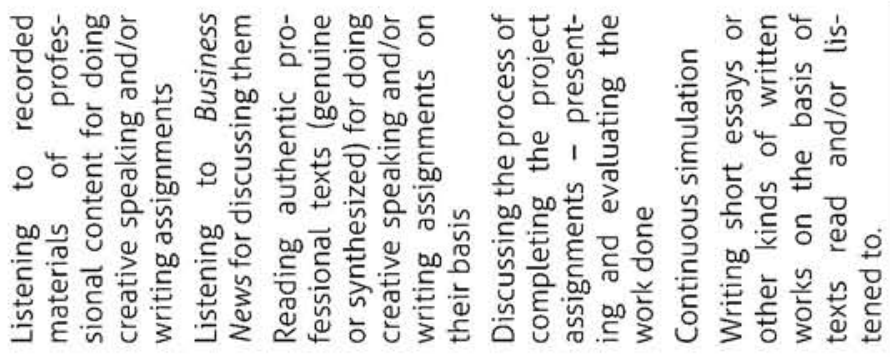 \\
\hline$m$ & 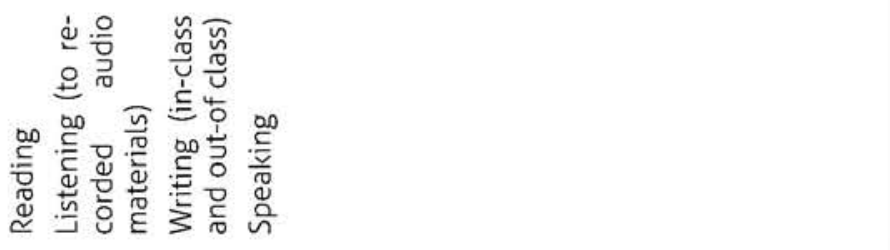 \\
\hline$N$ & 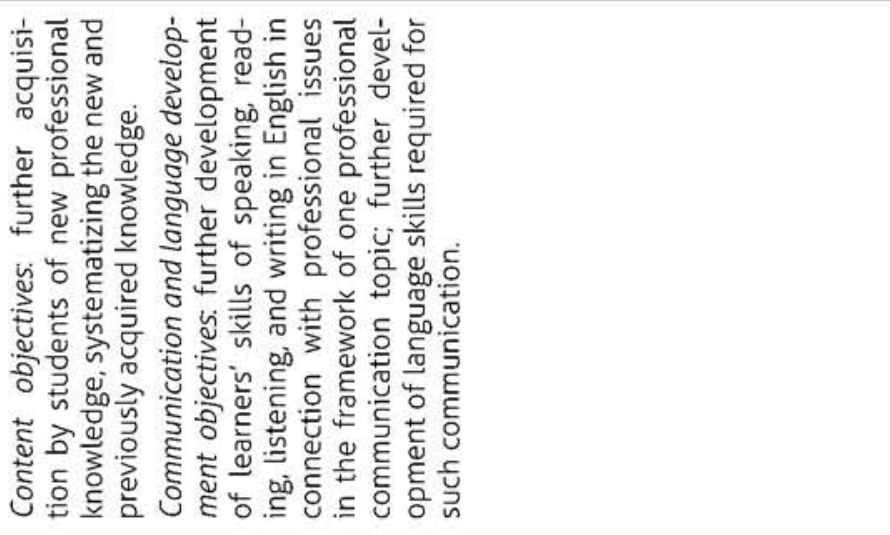 \\
\hline - & 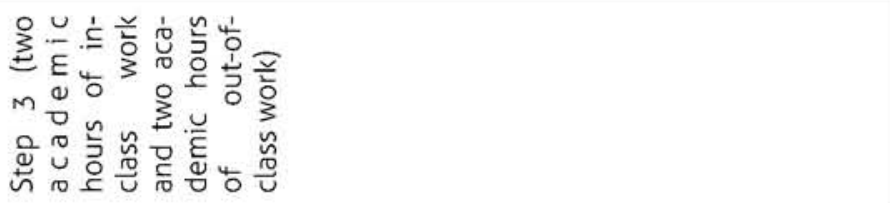 \\
\hline
\end{tabular}




\begin{tabular}{|c|c|}
\hline in & 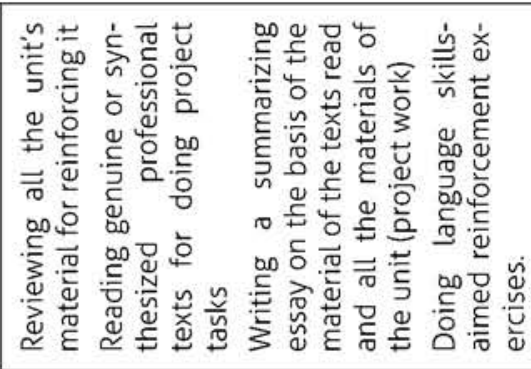 \\
\hline$\checkmark$ & 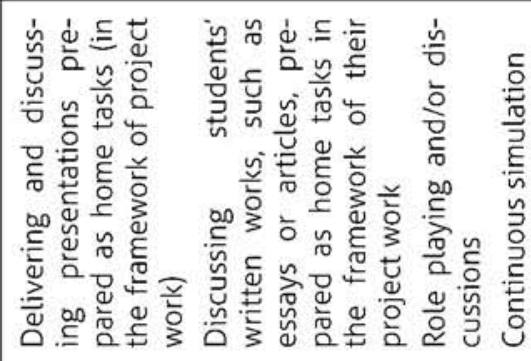 \\
\hline$m$ & 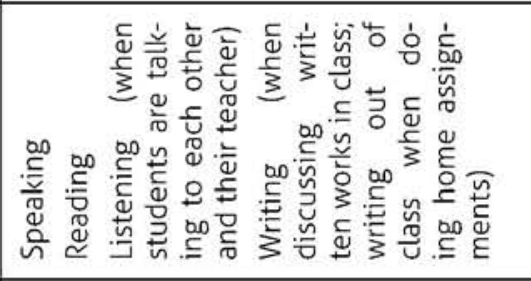 \\
\hline$N$ & 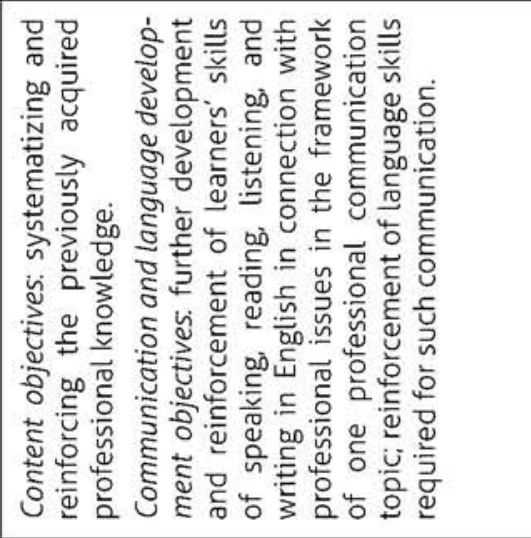 \\
\hline$-H$ & 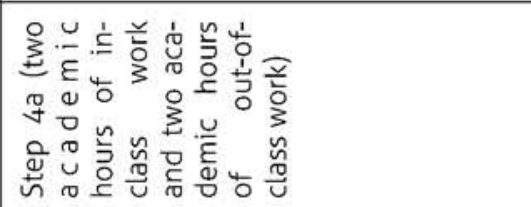 \\
\hline
\end{tabular}




\begin{tabular}{|c|c|}
\hline in & 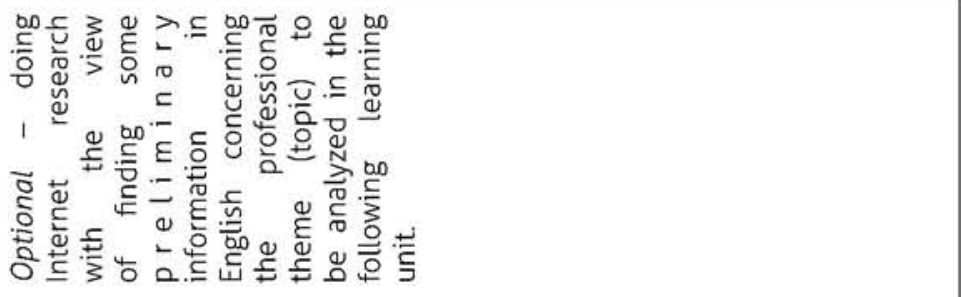 \\
\hline$\checkmark$ & 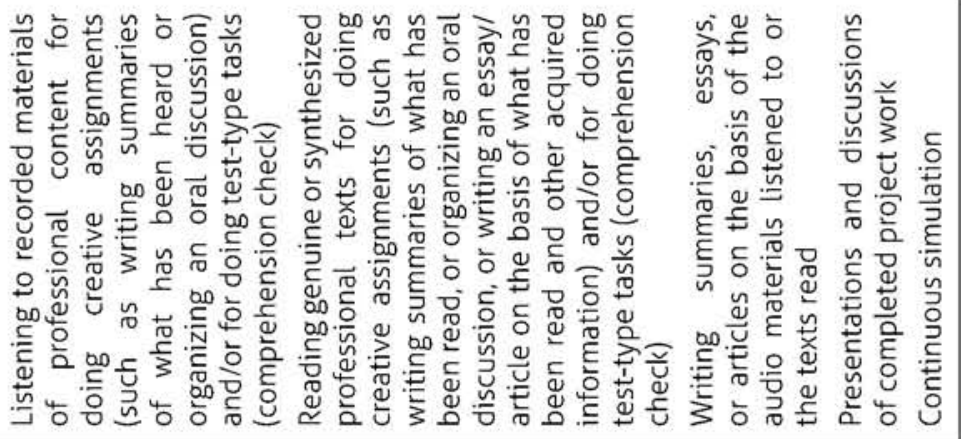 \\
\hline$m$ & 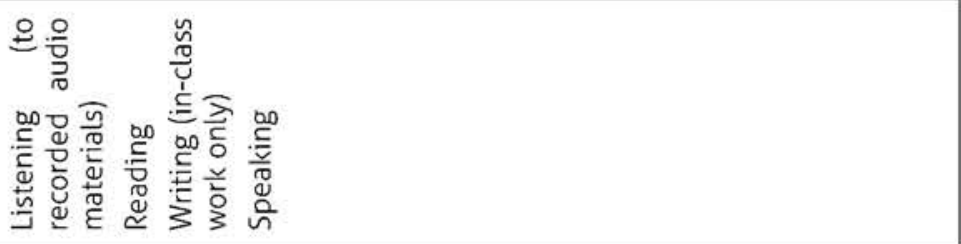 \\
\hline$N$ & 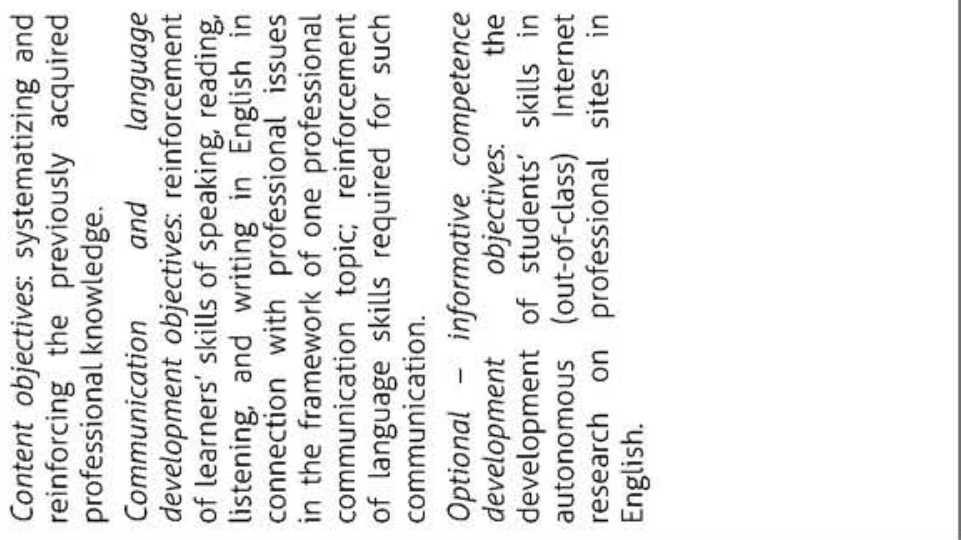 \\
\hline - & 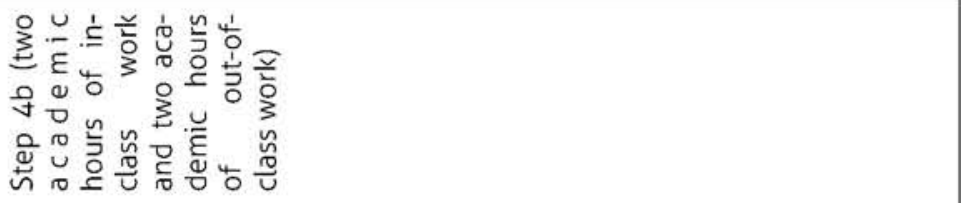 \\
\hline
\end{tabular}




\section{Similarities and differences between two versions of a constructivist ESP course: one for future psychologists and another one for future economists and businesspeople}

The common features of two constructivist ESP courses analyzed in this monograph are quite obvious:

1. Both courses are based on experiential interactive teaching/learning and use identical types and forms of learning activities (with the exception of mandatory Internet research and of continuous simulation - those exceptions to be discussed below among the differences).

2. Though in the courses' models in Tables 1 and 2 the content-based nature of courses can be seen only in the statements of content objectives, everything said in the preceding chapters also makes it clear that they are both totally content-based - to be more precise, totally theme-based in the framework of the content-based approach.

3. From what has been said in the preceding chapters and, partially, from Tables 1 and 2 above, it can be seen that four out of five principles of practical implementation of the constructivist approach to teaching English for specific purposes at tertiary schools equally form the practical foundation of both versions of ESP courses: the principle of systematizing professional information in the coursebook and course of English for Specific Purposes, the principle of authenticity of students' learning activities and learning communication, the principle of authenticity of learning materials, and the principle of integrating English speaking, listening, reading, and writing in the learning process. Only the last, fifth, principle, that of developing students' informative competence in English, which is fully implemented in the course and coursebook for future psychologists, may be said to be neglected in the coursebook and course for future economists and businesspeople. There is only a limited attempt there to take account of that principle in students' optional learning activities (see Table 2). This difference is also to be discussed below.

4. The structure and design similarities of both course models as they are shown in Tables 1 and 2 are quite striking. In fact, except for the two major differences caused by the already mentioned absence of mandatory Internet research in the second model and the absence of continuous simulation in the first model, both models could be considered as almost identical in all their other aspects with only minor differences. Indeed, the parts of learning units are very much alike in design; the objectives in every such part are identical (except for informative competence development objectives); the types of communicative activities (types of com- 
munication on professional issues) involved when working on structural parts of a typical learning unit are the same, as well as practically the same are the learning activities used in in-class and out-of-class students' work (again, except for continuous simulation not used in the first model and mandatory Internet research and other Internet-based activities not used in the second model).

All the similarities and common features of both ESP courses and both ESP coursebooks demonstrate that they belong to one and the same approach - the constructivist one, since the requirements of the two principal fundamental constituents of that approach (experiential interactive teaching/learning and content-based instruction - see Chapters 1 and 2) are fully met in each of the cases. But of the two courses and two coursebooks, only one ESP course, for future psychologists, and only one coursebook, Psychological Matters, are based on the blended learning approach to organizing teaching/learning. The ESP course for future economists and businesspeople and the coursebook Business Projects can in no way be said to represent this kind of learning. Nevertheless, the course and coursebook represent the constructivist approach. This is because, as emphasized several times, the blended learning in general and the Internet use in particular embody a subordinated (though basic) constituent of the approach, the one that substantially improves it but is not obligatory for its introduction into teaching practice.

It has also been reiterated that the reason for excluding blended learning from the ESP course and coursebook for future economists and businesspeople was quite natural in the historic perspective. That ESP course was launched in 2002 when the coursebook Business Projects (Tarnopolsky, Kozhushko, et al., 2002) was first published. It is approximately at the same time or even later that the first publications on blended learning, and, in particular, on blended learning in English language teaching first started to appear (c.f., for instance, Barrett, \& Sharma, 2003; Brennan, 2004; Grey, 2006; Sharma, 2003; Sharma, \& Barrett, 2007). Before that time, little had been heard about blended learning, so it by no means could have been included into our coursebook and the ESP course based on it. Due to the same reason, the principle of developing students' informative competence in English could not be one of the principles underlying the preparation of the coursebook Business Projects and the development of a corresponding ESP course. Including students' Internet research into their learning as an optional, not too frequent, and only out-of-class learning activity was the most that could be recommended at that time.

However, the design of an ESP coursebook and course with only optional and infrequent use of Internet-based learning activities (see Table 2 ) has had positive effects as well. The coursebook Business Projects and the ESP course designed on its basis have been functioning very successfully in a number of tertiary schools of Ukraine for more than 10 years already (see further). This has demonstrated 
the possibility of developing the suggested constructivist approach in two versions: the complete version (with blended learning), as embodied in the coursebook Psychological Matters, and the narrower version (without blended learning) as embodied in the coursebook Business Projects. The existence of such a narrower version that manifests the principal difference between two developed models of the constructivist ESP teaching/learning process may prove to be very important for some cases, namely, for those when the broad use of the Internet technology in the ESP course is not feasible due to different causes. Even in such a case, the constructivist approach can be effectively and successfully introduced if its introduction is based on the narrower version.

The other differences between the two models/versions of ESP courses discussed above (see Tables 1 and 2) also manifest the possibilities of developing different versions and modifications of those courses and coursebooks on the basis of the suggested constructivist approach.

The first of those differences has already been spoken about several times. It is the continuous simulation used in the ESP course for future businesspeople and not used when teaching ESP to future psychologists. The reason for this has also been explained in Chapter 1 (2.2.3). Continuous simulation matches very well the professional activities of future businessmen and businesswomen but does not match at all the activities of future practical psychologists. Therefore, in this case, the difference is due to the requirements of experiential teaching/learning, which presupposes the modeling of professional activities to be as accurate as possible, thus excluding those learning activities that do not help in imitating what is done in the framework of professional engagements.

It is due to the same reasoning that students' listening to Business News (important for future businesspeople - c.f. Chapter 2, 5.2.4) was included in the course and coursebook for future specialists in Economics and Business and not included in the other course and coursebook as irrelevant for future psychologists. But this difference is a minor one because in every learning unit of the coursebook Business Projects listening to Business News is practiced only once.

There are some other differences not mentioned before that should be ascribed to the same cause.

For instance, a careful comparison of Tables 1 and 2 shows that project work receives more attention in the course for economists and businesspeople because businessmen and businesswomen are always involved in some projects, while professional projects are a rarer occurrence in the work of practical psychologists.

On the other hand, case studies are more often used in the course for psychologists because their future professional activities involve the inevitability of analyzing their clients' cases every day - both in their current practical work and during seminars with colleagues. Also, as can be seen from Tables 1 and 
2 , future psychologists more frequently write summaries of the texts read or listened to because summarizing professional information obtained from reading professional literature or from listening to professional lectures, presentations, discussions, etc. is something they are going to do regularly in their jobs.

One more difference needs to be mentioned. If out-of-class activities from a typical learning unit in the course and coursebook for future psychologists are juxtaposed to the out-of-class activities in the course and coursebook for future economists and businesspeople, it will become obvious that in the latter course and coursebook there are more language skills-aimed (vocabulary and/or grammar) exercises to be done by students out of class than in the former ones. The reduction of the number of such exercises in the later coursebook and course for future psychologists was caused by the practical experience of using the coursebook and teaching the course for future economists and businesspeople. That experience demonstrated that when the constructivist approach had been introduced, the success in developing students' language skills mostly depended on the number and quality of experiential, creative, and totally communicative learning activities and much less on the number of specific language formfocused exercises. The latter ones should not be completely excluded, but their number can be reduced to a minimum. That finding allowed for the planning of fewer language skills-aimed (vocabulary and/or grammar) exercises for the later ESP course (for future psychologists) - increasing accordingly the number of students' experiential, creative, and communicative learning activities designed for their out-of-class work.

Other differences can be found in both courses and coursebooks exemplifying our approach, but even those already mentioned are sufficient to prove the most important point. Within the suggested approach there can be different modifications and versions of constructivist ESP courses: with a blended learning component or without it, with different experiential learning activities used according to the requirements of the future profession, and, most certainly, with different subject matter materials in the learning content, different thematic, situational, language, and other learning content components - also depending on the requirements of that profession.

The two courses and coursebooks discussed in this monograph are good examples to be quoted when illustrating the opportunities for developing such versions and modifications not only because they demonstrate quite a wide range of possible differences that may be introduced in accordance with needs, requirements, and local conditions. They also have behind them considerable successful experience of being used in teaching practice, proving the above statement. For instance, the coursebook Business Projects has already been involved in such practice for more than 10 years. As already mentioned, it was first introduced in Alfred Nobel University, Dnipropetrovsk, Ukraine in 2002. Since then, its second revised edition was published by one of the biggest 
Ukrainian publishing houses (c.f. Tarnopolsky, \& Kozhushko, 2007) and a number of Ukrainian universities have been successfully working with it for years. Those universities range from the gigantic leading universities in the country, such as the National Technical University of Ukraine "Kyiv Polytechnic Institute", to smaller regional branches of national universities, such as Vinnitsa Trade and Economics Institute of Kyiv National Trade and Economics University. These facts witness to the success of the coursebook and the ESP course designed on its basis.

The coursebook Psychological Matters and the corresponding ESP course for future psychologists do not have such a long history of teaching practice behind it because of the coursebook's recent publication. However, besides their complete success when used for teaching students of Psychology at Alfred Nobel University, Dnipropetrovsk, the interest in those particular coursebook and course is growing throughout the country. So, they may soon become as popular for teaching English to future psychologists as the coursebook Business Projects has become popular for teaching future businesspeople and economists.

Everything said in this chapter may be considered as proof of the fact that the developed approach to ESP teaching and learning at tertiary schools is not something rigid that can be used for teaching only definite categories of students in definite teaching/learning conditions. On the contrary, the approach is quite flexible allowing for development of its different versions and modifications that can be adjusted and adapted to different ESP teaching/learning conditions, programs, and various students' majors at different tertiary schools. This conclusion is the final one to be made in the monograph.

\section{Conclusion to Chapter 5}

In this chapter two developed versions of constructivist ESP coursebooks and ESP courses based on them have been discussed, compared, and contrasted: one earlier coursebook and course designed for future economists and businesspeople and the other later one designed for future psychologists.

Both ESP courses have been shown to be quite adequate when representing in practice the constructivist approach to ESP teaching/learning suggested in this monograph. However, only the ESP course (and the coursebook on which it is based) for future psychologists is considered to embody the complete version of the approach in which the constructivist teaching/learning is integrated with blended learning so that Internet-based activities occupy a considerable place in the process of ESP acquisition by tertiary students. The earlier ESP course and coursebook for future economists and businesspeople embodies a narrower version of the approach which, remaining totally constructivist and quite akin 
to the later complete version, yet has no blended learning constituent included into it. Creating such a narrower version had been due to objective causes and circumstances but, as it later turned out, having it in the ESP teacher's pedagogical arsenal, may prove to be of considerable practical importance in cases when broad use of Internet technologies in the ESP teaching/learning process is not feasible.

Other differences between the two versions of the constructivist approach to ESP teaching/learning have been discussed in the chapter. It has been shown that such differences are due to different professional requirements to ESP courses when students of different majors are taught English for professional communication.

On the basis of the analysis of two different versions of one and the same constructivist approach, the general conclusion has been made in the chapter that the suggested approach is sufficiently flexible to allow developing its different versions and modifications which can be adjusted and adapted to different ESP teaching/learning conditions, programs, and various students majors at different tertiary schools. 